\title{
LA ACELERADA TRAMITACIÓN PARLAMENTARIA DE LA REFORMA DEL ARTÍCULO 135 DE LA CONSTITUCIÓN (Especial consideración de la inadmisión de enmiendas. Los límites al derecho de enmienda en la reforma constitucional)
}

\author{
PIEDAD GARCÍA-ESCUDERO MÁRQUEZ \\ Letrada de las Cortes Generales \\ Catedrática de Derecho Constitucional \\ Universidad Complutense de Madrid
}

SUMARIO.

I. La tramitación acelerada de la reforma

II. La inadmisión de enmiendas

III. Conclusión

\section{LA TRAMITACIÓN ACELERADA DE LA REFORMA}

\section{Cronología del iter PARLAMENTARio}

En un tiempo breve, coincidente — como la primera y hasta ahora única reforma ${ }^{1}$ en parte con el período vacacional de verano, se ha aprobado la segunda reforma de la Constitución española de 1978 en sus treinta y tres años de vigencia.

Sin perjuicio de la importancia del debate sobre su contenido, los aspectos procedimentales de la reforma también ofrecen interés, dado el escaso número de ellos que han tenido lugar por la premura en su tramitación. A uno de estos aspectos, la inadmisión de

1 La Proposición de ley (sic) de reforma del artículo 13, apartado 2, de la Constitución española, adoptada por todos los grupos parlamentarios y presentada el 7 de julio de 1992 (BOCG Congreso, Serie B, n 147-1, de 9 de julio), fue tomada en consideración por el Pleno de la Cámara el 13 de julio, tramitándose por el procedimiento de lectura única y siendo aprobada por el Pleno el 22 de julio. En el Senado, es remitida a la Comisión de Constitución el 23 de julio [BOCG Senado, Serie III-B, no 24 a), de esta fecha], tramitándose por el procedimiento de urgencia. No se presentaron enmiendas, el dictamen de la Comisión fue aprobado el 28 de julio y el Pleno aprobó la reforma el día 30. Transcurrido el plazo de quince días previsto por el artículo 167 de la Constitución para solicitar la celebración de referéndum, el texto de la reforma fue sancionado por el Rey el 27 de agosto y publicado en el Boletín Oficial del Estado el 28 de agosto de 1992. 
enmiendas, voy a dedicar especial atención, dada su conexión con el derecho de enmienda como núcleo de la función representativa de los parlamentarios.

Merece, no obstante, algo más que un simple comentario la celeridad en la tramitación de la reforma: transcurren trece días desde la presentación el 26 de agosto de 2011 y publicación el mismo día de la Proposición de reforma de los Grupos parlamentarios Socialista y Popular en el Boletín Oficial de las Cortes Generales (BOCG Congreso, $\mathrm{n}^{\circ}$ 329.1) hasta su aprobación por el Senado el día 8 de septiembre. La pequeña pausa que se abre a continuación se debe a la posibilidad de solicitud de referéndum en el plazo de quince días, otorgada por el artículo 167.3 de la Constitución a una décima parte de los miembros de cualquiera de las Cámaras. Transcurrido dicho plazo, el 27 de septiembre de 2011, un mes y un día después de la presentación de la iniciativa, la reforma es sancionada por el Rey y publicada en el Boletín Oficial del Estado, entrando en vigor el mismo día ${ }^{2}$.

La mera descripción de este iter nos lleva a plantearnos, como haremos en el epígrafe siguiente, si los procedimientos seguidos son los más adecuados para la primera reforma de calado (la de 1992, aun importante en cuanto al fondo, se solventaba en dos palabras) que se aprueba en la historia de nuestra Constitución.

La inadmisión por el Tribunal Constitucional del recurso de amparo interpuesto por los diputados del Grupo parlamentario ERC-IU-ICV Gaspar Llamazares y Nuria Buenaventura ${ }^{3}$, en el que se impugnaba la inadecuada tramitación de la reforma como lesiva de los derechos reconocidos en el artículo 23 de la Constitución, no obsta a que se examinen y en su caso critiquen — desde otros parámetros - los procedimientos utilizados.

Veamos las especificidades de tramitación seguidas por la Proposición de reforma del artículo 135 de la Constitución española:

\section{a) Congreso de los Diputado: 8 días. Urgencia y lectura única}

La Proposición es presentada por los Grupos Parlamentarios Socialista y Popular el 26 de agosto de 2011. Los Grupos autores de la Proposición de reforma constitucional solicitan en el escrito de presentación su tramitación por el procedimiento de urgencia, así

2 No es casual que ese mismo día se publicara en el BOE (la reforma constitucional aparece en un segundo Boletín de la misma fecha) y entrara en vigor el Real Decreto 1329/2011, de disolución del Congreso de los Diputados y del Senado y de convocatoria de elecciones.

3 Auto 9/2012 de 13 de enero, dictado en el recurso de amparo 5241/2011, contra Resolución de la Mesa del Congreso de los Diputados de 30 de agosto de 2011, Acuerdo de la misma Mesa de 2 de septiembre de 2011, Acuerdo del Pleno del Congreso de los Diputados de 30 de agosto de 2011 y Acuerdo de la Mesa de 1 de septiembre de 2011, recaídos todos ellos en relación con la tramitación parlamentaria de la proposición de reforma del art. 135 CE. A propuesta de la Sala Segunda, el Pleno del Tribunal recabó para sí, conforme al art. 10.1.n) de la LOTC, el conocimiento del recurso. El Magistrado Pérez Tremps, en un voto particular de gran interés que compartimos, plantea que la decisión sobre el recurso debería haber sido objeto de una sentencia, previo el procedimiento correspondiente, pues en el Auto de inadmisión el Tribunal no ha realizado un juicio liminar, sino de manifiesta complejidad técnica y trascendencia constitucional, en cuanto versa sobre una cuestión sin casi previa doctrina constitucional, dada su novedad, como es el desarrollo del procedimiento parlamentario de reforma constitucional y la posición de los representantes del pueblo en ese procedimiento, y por tanto de los derechos fundamentales del artículo $23 \mathrm{CE}$, que debería haber sido objeto de un pronunciamiento más reposado y tras un análisis procesalmente completo de las cuestiones planteadas. 
como su aprobación eventual —una vez tomada en consideración — por lectura única por el Pleno de la Cámara.

Junto a este escrito se presenta otro firmado por un número de diputados de los Grupos Socialista y Popular que representan la mayoría absoluta de los miembros de la Cámara, por el cual solicitan, al amparo de los arts. 73.2 de la Constitución y 61 del Reglamento del Congreso, la convocatoria del Pleno de la Cámara [en sesión extraordinaria] para la toma en consideración de la Proposición y adopción del acuerdo de tramitación directa y en lectura única.

El mismo día, la Presidencia de la Cámara, en ejercicio de la delegación conferida por la Mesa al inicio de la legislatura, admite a trámite el escrito, ordena su publicación (que se realiza el mismo día de su presentación —algo absolutamente inusual— en el BOCG Congreso n 329-1) y acuerda someterlo a la deliberación del Pleno a efectos de su toma en consideración, así como su traslado al Gobierno para que manifieste su criterio respecto de la toma en consideración.

En escrito del propio día 26 de agosto presentado en el Congreso el mismo día, el Secretario de Estado de Asuntos Constitucionales y Parlamentarios comunica la conformidad del Gobierno (que según el artículo 126.3 del Reglamento del Congreso dispone de treinta días para emitir su criterio y su disconformidad con la tramitación de las proposiciones de ley — precepto que se aplica, en cuanto a lo primero, a las proposiciones de reforma constitucional no agravada en virtud de la remisión contenida en el artículo 146.1-), a la tramitación de la iniciativa de reforma. De esta forma, la proposición queda en condiciones de ser incluida en el orden del día del Pleno (126.3 RC) para su toma en consideración.

El 30 de agosto de 2011, en sesión extraordinaria, el Pleno del Congreso acuerda tomar en consideración la Proposición de reforma, así como su tramitación directa y en lectura única. Previamente, la Mesa había decidido ese mismo día, para el caso de que el Pleno adoptase los citados acuerdos, su tramitación por el procedimiento de urgencia y la apertura de un plazo de presentación de enmiendas hasta dos días después, el 1 de septiembre de 2011 a las 14 horas, todo lo cual se publica en el BOCG el día 31 (BOCG Congreso $\mathrm{n}^{\circ} 329-2$ ).

En turno en contra de la Proposición de reforma en el debate de toma en consideración intervinieron los representantes de los Grupos parlamentarios de Convergencia i Uniò, Sr. Durán i Lleida, y de ERC-IU-ICV, Sres. Ridao y Llamazares ${ }^{4}$. En lo que a las razones de procedimiento se refiere, el primero afirmó que se había producido una ruptura del proceso constituyente, por cuanto «modificar la Constitución requiere sosiego y consenso y es impresentable e inadmisible que se haga una reforma exprés de la Constitución en cuatro días». También el Sr. Ridao (recalcando que «en democracia las formas son también parte del contenido») destaca que «PP y PSOE... se despachan en una sola semana y con sordina toda una reforma constitucional». El Sr. Llamazares, que considera vulnerado el derecho de participación y representación política de los parlamentarios, declara: «Una reforma constitucional, señorías, no se puede presentar en agosto con

4 Diario de Sesiones Congreso n ${ }^{\circ} 269$, de 30 de agosto de 2011. Puede accederse a las publicaciones oficiales que reflejan la tramitación de la reforma en el Portal de la Constitución de la página web del Congreso de los Diputados: www.congreso.es/consti/constitucion/reforma/segunda_reforma. 
agosticidad y alevosía. Una reforma constitucional no se puede tramitar en cuarenta y ocho horas. Una reforma constitucional no puede hacerse mediante el trámite de lectura única. Si hay algo esencialmente parlamentario es la enmienda, la negociación, el acuerdo, la transacción y, finalmente, la votación. Ustedes nos quitan buena parte de nuestra libertad y buena parte de nuestra representación parlamentaria».

A estos reproches sobre la forma en que se ha tramitado la reforma responde el portavoz del Grupo Socialista, Sr. Alonso, que «lo necesitamos ahora y ya», y la portavoz del Grupo Popular, Sra. Sáez de Santamaría, que la premura no es responsabilidad de su Grupo, pues lo habían reclamado hacía más de un año en la Cámara.

En turno de fijación de posiciones, los representantes de otros grupos parlamentarios también inciden en el mismo tema. Según el Sr. Erkoreka, la reforma «supone un atropello en toda regla a los procedimientos democráticos», pues «no es de recibo que se pretenda tramitar una reforma constitucional en peores condiciones de transparencia, publicidad y contraste público que las establecidas con carácter general para las leyes ordinarias». Más adelante, censura el procedimiento de lectura única para una reforma constitucional y el que los dos grupos promotores de la iniciativa «no se conformaban con tramitar el procedimiento a uña de caballo, además querían privarnos de la posibilidad de presentar enmiendas, todo precipitadamente y a hurtadillas», siendo lamentable que al final, por decisión de la Mesa, el plazo sea de cuarenta y ocho horas para su presentación ${ }^{5}$.

La toma en consideración fue aprobada por 318 votos a favor, 16 en contra y 2 abstenciones ${ }^{6}$. A continuación, la tramitación directa por lectura única ante el Pleno de la Cámara fue aprobada por 319 votos a favor y 17 en contra ${ }^{7}$.

En el plazo señalado se presentaron 24 enmiendas, siete de las cuales fueron inadmitidas por la Mesa de la Cámara ${ }^{8}$ y de otras se solicitó reformulación, lo que fue cumplimentado mediante escritos del Grupo Mixto (Sras. Barkos y Díez) y ERC-IU-ICV (BOCG Congreso no 329-3, de 5 de septiembre de 2011). A la inadmisión de enmiendas dedicamos el apartado II de este trabajo.

También se presentó una solicitud de la Sra. Buenaventura Puig y el Sr. Llamazares Trigo, de reconsideración de la decisión adoptada por la Mesa en relación con la trami-

5 No recogemos las intervenciones críticas relativas a la no celebración de referéndum, por fundarse en motivaciones políticas de fondo y no procedimentales.

6 Votaron a favor de la toma en consideración los diputados de PP y PSOE (con la excepción del diputado Antonio Gutiérrez, que se opuso) y UPN; en contra, los diputados de PNV, ERC-IU-ICV, BNG, UPyD, Nafarroa Bai y el citado diputado socialista. Se abstuvieron los dos diputados de Coalición Canaria (Grupo Mixto). No participaron en la votación los diez diputados de $\mathrm{CiU}$ «en señal de protesta». Cuatro diputados del Grupo Popular no asisten al Pleno (Fuente: El País, El Mundo y ABC de 31 de agosto de 2011).

7 En esta segunda votación votó a favor el diputado Antonio Gutierrez y en contra los dos de Coalición Canaria ( $A B C$ de 31 de agosto de 2011).

8 La calificación de enmiendas corresponde a la Mesa de la Cámara porque no interviene ninguna Comisión en el procedimiento de lectura única. En el procedimiento ordinario o en el descentralizado en Comisión, sería la Mesa de este órgano la competente para calificar las enmiendas presentadas, de conformidad con la Resolución de la Presidencia sobre normas que regulan la calificación de los escritos de enmiendas presentadas a textos legislativos, de 12 de enero de 1983, que se refiere sólo a la calificación de enmiendas a la totalidad, así como de las que supongan aumento de los créditos o disminución de los ingresos presupuestarios. Contra el acuerdo de calificación de la Mesa de la Comisión, el diputado o grupo parlamentario enmendantes pueden interponer reclamación, dice la Resolución, ante la Mesa de la Cámara. En el supuesto que examinemos, el recurso ante la Mesa se articula como una solicitud de reconsideración al amparo del artículo 31.2 del Reglamento del Congreso. 
tación de la Proposición de reforma, que fue desestimada por la Mesa en su reunión del día 2 de septiembre.

El Pleno del Congreso celebró sesión ordinaria el viernes 2 de septiembre de 2011 para el debate y votación de la proposición de reforma constitucional. En lo que se refiere a la celeridad del procedimiento, la Sra. Barkos Berruezo, del Grupo Mixto, manifiesta que a esas horas de la mañana los portavoces se seguían cuestionando si efectivamente las enmiendas presentadas no vetadas habían sido aceptadas o no en su reformulación?

La inadmisión de enmiendas es alegada por algún portavoz como motivo para ausentarse de las votaciones ${ }^{10}$, lo que realizarán posteriormente miembros de distintos grupos parlamentarios.

En el curso de la sesión plenaria, se da lectura a dos enmiendas transaccionales presentadas por los Grupos Socialista y Popular, autores de la iniciativa de reforma ${ }^{11}$, a la enmienda número 17 y a las enmiendas números 18 y 19 del Grupo $\mathrm{CiU}^{12}$.

9 También el portavoz del Grupo EAJ-PNV, Sr. Erkoreka, alude en su intervención a la inadmisión de enmiendas: «Si el Partido Socialista y el Partido Popular tienen propuestas para la reforma constitucional, también nosotros tenemos las nuestras, aunque ya veo que, en virtud de la ley del embudo, las suyas se pueden defender y las nuestras se pueden explicar pero no se pueden defender porque son inadmitidas a limine. La enmienda recogía en lo esencial la declaración que el Pleno del Parlamento vasco hizo el año 1990 a favor del derecho de autodeterminación». A esta enmienda se refiere posteriormente como «la enmienda vetada».

10 Véase la intervención al inicio de las votaciones del Sr. Jorquera Caselas (Diario de Sesiones no 270, de 2 de septiembre de 2011, pág. 17) en la que retira la enmienda a la totalidad presentada por BNG debido a su profunda discrepancia «con el método, con la inadmisión de una serie de enmiendas» y anuncia que van a ausentarse de las votaciones. «En el mismo tono», la señora Barkos retira la enmienda presentada por Nafarroa Bai. A continuación, el Presidente del Congreso dice en dos ocasiones que el momento de ausentarse de la sala — «tal y como me han anunciado antes del inicio de la sesión»— es el anterior al inicio de las votaciones, antes de que se cierren las puertas. El Diario de Sesiones indica que «varias señoras y señores diputados abandonan el salón de plenos».

11 No existe norma alguna que exija que las enmiendas provengan de grupos distintos al autor de la iniciativa, siendo frecuentes las llamadas «autoenmiendas», especialmente de carácter transaccional. De ellas se olvida la definición de enmienda de BIGLINO CAMPOS, P., («Enmienda en el procedimiento legislativo», Enciclopedia jurídica básica, vol. II, Civitas, Madrid, 1995, pág. 2803) como «las propuestas mediante las cuales se pretende influir en las iniciativas legislativas que provienen de otros titulares, solicitando su rechazo, su modificación total o parcial o la adición de cuestiones no previstas». Las autoenmiendas son muy frecuentes, sobre todo en fases posteriores del procedimiento, pero también en el plazo inicial de presentación de enmiendas, si son proposiciones parlamentarias. Puede decirse que materialmente, si no formalmente, tienen también este carácter las enmiendas (a veces muy numerosas) que presenta el grupo que apoya al Gobierno a los proyectos remitidos por éste.

12 Con estas enmiendas transaccionales se pretendía alcanzar un acuerdo parcial con Convergencia. Enmienda transaccional a la enmienda 17 de CiU: El apartado 6 del artículo 135 de la Constitución queda redactado como sigue: «6. Las Comunidades Autónomas, de acuerdo con sus respectivos Estatutos y en el marco de la autonomía financiera reconocida en esta Constitución, adoptarán las disposiciones que procedan para el desarrollo y aplicación de los mecanismos para el cumplimientos del principio de estabilidad presupuestaria, dentro de los límites a que se refiere este artículo». Enmienda transaccional a las enmiendas 18 y 19 de CiU: De adición de una nueva letra c) al apartado 5 del artículo 135 de la Constitución, pasando la actual letra c) a letra d). La letra c) del apartado 5 del artículo 135 queda redactada como sigue: «c) Los mecanismos que permitan el cumplimiento del límite de deuda a que se refiere el apartado 3 anterior». Y, en consecuencia, la Disposición Adicional única pasa a ser Disposición transitoria décima de la Constitución Española con el siguiente contenido: «Disposición transitoria décima. 1. Los límites de déficit estructural establecidos en el artículo 135.2 de la Constitución española entrarán en vigor a partir de 2020. 2. La Ley Orgánica prevista en el artículo 135 de la Constitución Española deberá estar aprobada antes de 30 de junio de 2012». 
De conformidad con el artículo 118.3 del Reglamento del Congreso, para la admisión a trámite de enmiendas de transacción entre las ya presentadas y el texto del dictamen en la sesión plenaria se requiere que ningún grupo parlamentario se oponga a su admisión y que ésta comporte la retirada de las enmiendas respecto de las que se transige. El Sr. Llamazares manifiesta su oposición a la tramitación — como contrapartida, según sus declaraciones públicas, a la falta de consenso en la tramitación de la reforma-, con lo que las enmiendas transaccionales no son sometidas a votación ${ }^{13}$.

El Presidente del Congreso propone una «corrección lingüística formal», consultada a la Real Academia de la Lengua, consistente en la sustitución de la expresión «en relación al» por «en relación con». Ningún diputado se opone a la admisión de esta corrección, que se incorpora al texto de la reforma.

Rechazadas todas las enmiendas, la Proposición de reforma es sometida a votación de conjunto, prescrita por el artículo $150 \mathrm{RC}$ para la tramitación por lectura única y como votación final por el artículo 146.2 para la reforma constitucional, exigiéndose el voto favorable de los tres quintos de los miembros de la Cámara. La Proposición es aprobada por 316 votos a favor y 5 en contra, no votando o hallándose ausentes 29 diputados $^{14}$.

La aprobación por el Pleno del Congreso de los Diputados se publica en el BOCG n ${ }^{\circ}$ 329-4, de 6 de septiembre de 2011.

\section{b) Senado: 5 días}

El mismo día 2 de septiembre se remite al Senado el texto aprobado por el Congreso de los Diputados relativo a la Proposición de reforma del artículo 135 de la Constitución española, que se publica en el BOCG Senado el día 3 (sábado), ordenándose la remisión a la Comisión Constitucional y abriéndose un plazo para la presentación de enmiendas hasta el 5 de septiembre (lunes), a las 20 horas.

Al mismo tiempo se publica el calendario de tramitación, que incluye los dos trámites anteriores y los siguientes: reunión de la Comisión, 6 de septiembre a las 13 horas; plazo de presentación de votos particulares, hasta las 20 horas del mismo martes 6 de septiembre; aprobación por el Pleno el 7 de septiembre.

13 El señor Llamazares permanece en el hemiciclo cuando lo abandonan los diputados de su grupo porque el Presidente no le concede la palabra antes de las votaciones para oponerse a la tramitación de las enmiendas transaccionales, sino sólo en el momento en que éstas van a someterse a votación. El Sr. Duran i Lleida pregunta si es una oposición personal o de todo el grupo y por tanto también de los diputados de Esquerra Republicana de Catalunya, pero el Presidente no concede el uso de la palabra al Sr. Llamazares para contestar, afirmando que seguro que «al acabar la sesión plenaria, tendrá la cortesía de informar a su Señoría [el Sr. Durán] de lo que le interesa». Una vez formulada su oposición a la tramitación de las dos enmiendas transaccionales, indica el Diario de Sesiones que el Sr. Llamazares abandona el escaño, aunque el Presidente aclara que «no va a poder salir del salón de sesiones» [hasta que concluyan las votaciones], lo que es acogido con risas.

14 Abandonan sus escaños los diputados de ERC-IU-ICV (salvo el Sr. Llamazares), BNG y Nafarroa Bai. Los diputados de CiU y PNV permanecen en sus escaños pero no participan en la votación (tampoco Llamazares) «como protesta por el pacto entre los dos grandes» (ABC y El Mundo, 3 de septiembre de 2011). Tres diputados socialistas, M. de la Rocha, J.A. Pérez Tapias y J.A. Barrio, se ausentaron para mostrar su disconformidad (misma fuente). También estaban ausentes dos diputados del Grupo Popular. Los votos en contra son de los dos diputados de Coalición Canaria, de dos diputados socialistas (Antonio Gutiérrez y otro por error, según fuentes periodísticas) y de la diputada de UPyD Rosa Díez. 
Los grupos parlamentarios del Senado presentan 29 enmiendas, de las cuales (según se publica en el BOCG Senado $n^{\circ} 108$, de 8 de septiembre de 2011, pág. 2) la Mesa, en su reunión del día 6 de septiembre inadmite cinco, inadmisión que podía ser objeto de reconsideración hasta las 20 horas del mismo día.

La Comisión Constitucional se reúne el propio día 6, aceptando como dictamen el texto remitido por el Congreso (BOCG Senado $n^{\circ} 107$, de 7 de septiembre de 2011, pág. 2) por 23 votos a favor (PSOE, PP y el portavoz de ECP, Ramón Aleu) y 1 en contra (Coalición Canaria) $)^{15}$.

En la defensa de sus enmiendas, el portavoz del Grupo Catalán de Convergencia i Uniò, Sr. Alturo Lloan, se pregunta: «¿Por qué tanta prisa? ¿Por qué no ha habido diálogo? ¿Por qué no se cuenta con nosotros? ¿Dónde está el consenso? Modificar la Constitución requiere calma, requiere sosiego y, sobre todo, consenso, y es inaudito que se haga una reforma de la Constitución en cuatro días» ${ }^{16}$.

Los Grupos parlamentarios Mixto (Coalición Canaria), Catalán en el Senado de Convergencia i Unió, Entesa Catalana de Progrès y Senadores Nacionalistas presentan votos particulares para la defensa de sus enmiendas en Pleno (BOCG $\mathrm{n}^{\circ} 108$, de 8 de septiembre de 2011, págs. 3 y 4).

El Pleno del Senado, en su sesión del día 7 de septiembre de 2011, debate el dictamen de la Comisión Constitucional y las enmiendas presentadas — con alusiones parecidas a las formuladas en el Congreso sobre la tramitación parlamentaria acelerada y la inadmisión de enmiendas ${ }^{17}$ - y lo aprueba por 233 votos a favor y 3 en contra ${ }^{18}$, previo rechazo de todas las enmiendas votadas, habiendo retirado el Sr. Pérez Bouza la enmienda ${ }^{\circ}$ 20, de supresión al texto acordado en el Congreso, «dado el posicionamiento de los distintos Grupos».

Las votaciones relativas a las enmiendas arrojan un número de hasta 247 votos

15 El Mundo y El País, 7 de septiembre de 2011. No participan en la votación, aun presentes en la sala, los senadores de PNV y CiU.

16 Véase el Diario de Sesiones de la Comisión Constitucional n ${ }^{\circ} 561$. Las enmiendas son rechazadas por 23 votos frente a 2 (las del Sr. Quintero) o 3 (las de los Grupos SN, CiU y ECP).

17 Así, en cuanto a la tramitación acelerada, el Sr. Pérez Bouza, del Grupo Senadores Nacionalistas: «...la tramitación parlamentaria de esta reforma es impropia de una reforma de la máxima ley, de la ley más importante que en este momento tiene el Estado español: la Constitución. Incluso tendría serias dudas de que esta tramitación parlamentaria atropellada fuera la propia para reformar una ley de un rango muchísimo menor, como puede ser una ley ordinaria. Esto parece más propio para reformar una orden ministerial o una circular administrativa, pero nunca para una reforma constitucional. El procedimiento que ustedes, Partido Popular y Partido Socialista, han escogido, lo que demuestra, señorías, es una falta de respeto absoluta por los ciudadanos, por el debate parlamentario y por una técnica legislativa mínimamente rigurosa» (Diario de Sesiones del Senado, Pleno, ${ }^{\circ} 130$, de 7 de septiembre de 2011, pág 7767).

En cuanto a la inadmisión de enmiendas, el senador Zubía, del mismo Grupo: «Los argumentos —si se pueden considerar como tales - ahora esgrimidos, igual que los de entonces [en el Congreso], se nos antojan meras disculpas que no tienen otro objeto que evitar la enmienda; evitar que se debata y, sobre todo, que se vote. Y simplemente quiero señalar que la enmienda pretendía alcanzar en el año 2011 lo que no fue posible en 1978, es decir una enmienda que no buscaba sino solucionar el conflicto vasco» (pág. 7759).

18 Votan a favor los diputados de PSOE, PP y UPN. En contra, Coalición Canaria y Foro Asturias. Se ausentan cuatro senadores: tres de ERC y uno de BNG abandonan la sala antes de la votación. Otros 12 senadores (7 de CiU, 3 de PNV y 2 de ICV) asisten al debate pero no votan. No acudieron 3 senadores del PSOE (dos de ellos, I. Zubero y R. Lerxundi, habían anunciado su oposición a la reforma), 2 del PSC, 3 del PP y 1 de CiU (Fuente: El País, 8 de septiembre de 2011). 
emitidos, que descienden a 236 en la votación final sobre el conjunto del texto de la reforma.

El 8 de septiembre se publica en los Boletines de Congreso y Senado ( $n^{\circ} 329-5$ y 108, respectivamente) la apertura del plazo previsto en el artículo 167 de la Constitución, que concluiría el 26 de septiembre de 2011, dentro del cual una décima parte de los miembros de una u otra Cámara podían solicitar que la reforma aprobada por las Cortes Generales fuera sometida a referéndum para su ratificación.

En este plazo de quince días presentan petición de celebración de referéndum 29 diputados de los Grupos EAJ-PNV (6), CiU (10), ERC-IU-ICV (5), Socialista (2, Sres. Rascón y Gutiérrez) y Mixto (1 Nafarroa Bai, 1 UPyD, 2 Coalición Canaria, 2 BNG). No se alcanza en consecuencia el número requerido de 35 diputados.

En el Senado, presentaron escritos de solicitud de referéndum los 7 senadores del Grupo Catalán en el Senado de Convergencia i Unió, sin que se alcanzara por tanto tampoco el mínimo requerido de 27 senadores, lo que es objeto de publicación en el BOCG Senado $\mathrm{n}^{\circ} 121$, de 27 de septiembre como «no solicitud de referendum para la ratificación».

Concluido el plazo de quince días, el día 27 de septiembre de 2011 en un acto solemne el Rey sanciona la reforma constitucional, publicándose ese mismo día en el Boletín Oficial del Estado $\left(\mathrm{n}^{\mathrm{o}} 233\right)^{19}$ y entrando en vigor también el mismo día, sin perjuicio de lo previsto en la disposición adicional única, apartado 3, para los límites de déficit estructural establecidos en el artículo 135.2, que entrarán en vigor a partir de 2020.

\section{LA TRAMITACIÓN DE LA REFORMA: ¿ES EL PROCEDIMIENTO EMPLEADO EL ADECUADO PARA UNA REFORMA DE LA CONSTITUCIÓN?}

He comenzado este trabajo comparando el timing de la segunda reforma constitucional con la primera, que tuvo lugar en 1992. Sin embargo, debemos destacar dos diferencias fundamentales entre ellas, que debieron haber influido en que fueran tramitadas de forma diferente: de una parte, la iniciativa de la primera fue suscrita por todos los grupos parlamentarios, mientras que la segunda se presenta como iniciativa de los dos grupos mayoritarios en el Congreso, que - tal como se desprende de las intervenciones en el debate- no ha sido consensuada con los demás; en segundo lugar, el contenido de la primera, tras la Declaración del Tribunal Constitucional de 1 de julio de 1992 sobre la adecuación a la Constitución del artículo 8B del Tratado de la Unión Europea, había que-

19 En un segundo Boletín del día 27 de septiembre publicado a mediodía. El fin del plazo de quince días coincide con el día de disolución de las Cámaras por el Presidente del Gobierno, publicándose y entrando en vigor al día siguiente el Real Decreto 1329/2011, de 26 de septiembre, esto es, el mismo día de la sanción y publicación de la reforma constitucional. En definitiva, todo el procedimiento expuesto se ha construido con el objetivo final de que el plazo de quince días concluya antes de la disolución, entre otras razones para obviar la problemática que ésta plantea: si el diez por ciento de miembros de la Cámara se computa, estando ésta disuelta, sobre el número de miembros de la Diputación Permanente; si a partir de la disolución están legitimados los miembros de las extintas Cámaras — ya no parlamentarios_ para solicitar el referéndum o sólo los que forman parte de dicha Diputación; o si el plazo debiera interrumpirse hasta la constitución de las nuevas Cortes. 
dado circuscrito a dos palabras — «y pasivo»— a introducir en el artículo 13.2 de la Constitución. Ni la simplicidad ni el consenso de la primera reforma concurren en la segunda, que hubiese requerido un mayor sosiego en la negociación y en la tramitación.

Dejando de lado la importancia política que presenta una reforma constitucional como la aprobada, vamos a centrarnos en el examen de los procedimientos reglamentarios utilizados.

\section{a) Congreso de los Diputados: lectura única y urgencia}

A solicitud de los Grupos parlamentarios autores de la iniciativa, la Proposición de reforma del artículo 135 de la Constitución se tramitó en el Congreso de los Diputados por los procedimientos de lectura única y urgencia.

\section{a.1. Procedimiento de lectura única}

El artículo 150 del Reglamento del Congreso regula como procedimiento legislativo especial el procedimiento de lectura única, que podrá ser acordado por el Pleno de la Cámara, a propuesta de la Mesa, oída la Junta de Portavoces. El procedimiento requiere, como hemos visto en el apartado anterior, un primer acuerdo del Pleno sobre el procedimiento, a partir del cual se abre un plazo de enmiendas - introducido por el uso, puesto que a ellas no se refiere el artículo $150 \mathrm{RC}$ - y una segunda sesión plenaria, en la que, según el Reglamento, el debate se sujeta a las normas establecidas para los de totalidad, sometiéndose seguidamente el conjunto del texto a una sola votación, de cuyo resultado depende que quede aprobado y se remita al Senado o que sea rechazado.

Nos interesa en este momento analizar la adecuación del procedimiento de lectura única para tramitar una reforma constitucional como la que nos ocupa.

La aplicación de este procedimiento es limitada por ambos Reglamentos (150 RC, 129 RS) a aquellos proyectos o proposiciones de ley cuya naturaleza lo aconseje o cuya simplicidad de formulación lo permita. La ambigüedad de esta determinación ha hecho que sea normalmente utilizado cuando existe un consenso tal sobre el contenido que es previsible que el texto no sea variado en el curso de la tramitación (sea o no simple su contenido), previo acuerdo de la Junta de Portavoces. Se emplea, pues, básicamente en tres casos:

- para la tramitación de proyectos o proposiciones de ley muy breves y sencillos, básicamente consensuados, que sería la previsión reglamentaria

- para la tramitación de proyectos o proposiciones sobre los que recae acuerdo unánime de tramitación particularmente acelerada por urgencia política en la promulgación de la ley ${ }^{20}$. Estos proyectos o proposiciones han llegado a culminar su tramitación en una semana en cada Cámara, cuando existe una voluntad política en este sentido (por ejemplo, medidas para víctimas del terrorismo)

20 Con excepciones que confirman la regla. Tal fue el caso de la tramitación por el procedimiento de lectura única de la Ley Orgánica 2/2004, por la que se modifica la Ley 6/1985, de 1 de julio, del Poder Judicial, en relación con la provisión de cargos por el Consejo General del Poder Judicial, pese a la oposición del Grupo Popular (véanse Diarios de sesiones del Congreso, de 2 de diciembre de 2004, y del Senado, de 13 de diciembre de 2004). 
- cuando se opta por este procedimiento, o así lo impone una ley, por introducirse un elemento pactista en la elaboración del proyecto o proposición (por ejemplo, las modificaciones de la LORAFNA o los acuerdos sobre concierto y cupo económico en las Comunidades Autónomas de Navarra y País Vasco). Al menos el segundo caso (previsión legal) incide negativamente sobre la soberanía legislativa de las Cámaras.

El procedimiento de lectura única suprime totalmente la fase de comisión (incluido el informe de la ponencia), de forma que, tras el plazo de enmiendas, se produce un debate y votación en el Pleno. Consigue por tanto la abreviación del procedimiento exactamente de forma contraria al procedimiento descentralizado en comisión, pues éste suprime la fase final del mismo, la aprobación por el Pleno, mientras que en la lectura única se suprimen las fases anteriores.

El procedimiento de lectura única es interpretado con mayor amplitud en la Cámara baja, donde se admite la presentación y votación de enmiendas, aunque el Reglamento sólo contempla una votación de conjunto. En el Senado, la rigidez que introduce la prohibición de presentar enmiendas al articulado ${ }^{21}$ (el artículo 129.3 RS únicamente permite la presentación de propuestas de veto) hace en la práctica menos utilizado este procedimiento, porque impide cualquier mínima variación en el texto ${ }^{22}$.

Esta podría haber sido una de las razones por las que el procedimiento de lectura única no se ha utilizado en el Senado para la tramitación de la reforma constitucional, aunque veremos a continuación que son otros imperativos reglamentarios los que lo impiden.

En el caso que nos ocupa, es evidente que el texto de la reforma del artículo 135 no puede ser calificado de simple en su formulación, ni tampoco existía acuerdo unánime so-

21 La STC 27/2000, de 31 de enero, desestima un recurso de amparo interpuesto por varios parlamentarios vascos contra el acuerdo de la Mesa que impone el procedimiento de lectura única a la tramitación de un proyecto sobre las aportaciones económicas de las Diputaciones Forales a los Presupuestos de la Comunidad Autónoma. El Tribunal recuerda la naturaleza negociada y paccionada de los proyectos de ley citados (de acuerdo con la doctrina sentada en la STC 76/1988), como justificación de la previsión del procedimiento legislativo especial de lectura única en el que no se admite la presentación de enmiendas. Esta prohibición no supone, según el Tribunal, una limitación o restricción ilegítima y desproporcionada, desde la perspectiva del art. $23 \mathrm{CE}$, al derecho de participación de los parlamentarios en la discusión y aprobación del proyecto de ley, puesto que las normas aprobadas por la Mesa permiten a los grupos parlamentarios presentar escritos de alegaciones en que manifiesten los motivos de discrepancia, así como disponer de un turno de intervención oral en el Pleno. En cambio, la STC 103/2008 declara la inconstitucionalidad de la Ley 9/2008 del Parlamento vasco, además de por motivos competenciales, por infringir el Reglamento del Parlamento Vasco en cuanto no se respetaron los «supuestos tasados» para hacer uso del procedimiento de lectura única, y «con infracción del RPV se ha impuesto a la Cámara la tramitación de la Ley impugnada a través de un procedimiento en el cual resultan notablemente limitadas las posibilidades de participación de las minorías en el proceso de elaboración de la norma, no por acuerdo unánime de la Mesa del Parlamento, sino en virtud de una decisión del Gobierno Vasco» (FJ 5).

22 En este sentido, cercena las posibilidades del Pleno del Senado, que no puede sino aceptar o rechazar el proyecto en bloque, sin introducir modificaciones. Precisamente el deseo de proteger el derecho de presentación de enmiendas hace que este procedimiento no sea utilizado en los supuestos en que hay divergencias políticas sobre el mismo, por muy «simple de formulación» (como dice el artículo 129 RS), breve o sencillo que sea, supuestos para los que sería muy adecuado, en particular por las características de celeridad que presenta la tramitación en el Senado. Bastaría con introducir en el Reglamento la posibilidad de presentación de enmiendas, aunque se limitara la legitimación a los grupos parlamentarios, para que fuera un procedimiento ágil susceptible de mayor utilización. 
bre su tramitación que augurara la no presentación de enmiendas o en escaso número, que no requirieran de un debate en la Comisión. No parece, por tanto que la lectura única fuera el procedimiento más adecuado. De hecho, puede decirse que su rigidez ha resultado contraproducente para los autores de la iniciativa — en la medida que les ha impedido llevar a término algunas negociaciones políticas emprendidas - por ser más rigurosa la admisión de enmiendas transaccionales en Pleno que en Comisión ${ }^{23}$.

El Auto 9/2012 de inadmisión del recurso de amparo presentado por dos diputados de IU, examina el procedimiento de lectura única, impugnado por los recurrentes como lesivo del ejercicio de las funciones parlamentarias, sin apreciar lesión en el proceder de la Mesa ni del Pleno, por cuanto «ni de la lectura del texto constitucional en su conjunto, ni de modo especial del Título X dedicado por la Constitución a su posible reforma, ni del artículo 146 RCD se advierte que la aprobación de la reforma constitucional haya quedado excluida del procedimiento de lectura única», en el que por otra parte —en cuanto a la alegada no reunión de las notas de simplicidad o naturaleza que lo aconseje«las normas aplicables (art. 150 RCD y concordantes) no establecen materias vedadas a dicha tramitación como sí sucede con el Reglamento parlamentario de alguna Asamblea autonómica». El procedimiento, además, ha sido acordado por el Pleno de la Cámara mediante la oportuna votación ${ }^{24}$.

Podemos estar de acuerdo en que no se ha lesionado el artículo 23. Nuestra crítica discurre por otros senderos quizá más políticos que jurídico-constitucionales.

\section{a.2. Procedimiento de urgencia}

Es común a los procedimientos abreviados su finalidad de obtener un acortamiento en la tramitación de los proyectos de ley, bien mediante una reducción de los plazos (urgencia), bien mediante una eliminación de trámites (lectura única y el procedimiento descentralizado en comisión, que por su especial configuración hemos optado por calificar de variante del procedimiento ordinario ${ }^{25}$ ).

Asimismo, comparten aquéllos como características la posibilidad de opción por el procedimiento que se presenta al órgano legitimado para decidir, si se cumplen los requisitos señalados por el Reglamento (en cuanto a la solicitud, simplicidad...), y su posible combinación con otros procedimientos, ordinarios o especiales. En este sentido ha-

23 En tres puntos se endurece el régimen de admisión de enmiendas en Pleno — 118.3 RC_-, respecto de las de Comisión, previstas en el artículo 114.3 RC: exige la retirada de las enmiendas sobre las que se transige, un grupo puede oponerse a su admisión y no caben las enmiendas in voce, tanto en su acepción coloquial de enmiendas que no se apoyan en otra respecto de la que se transige para conseguir la aproximación al texto del dictamen, como en su acepción real de enmiendas formuladas de viva voz por los oradores en el curso del debate.

24 El voto particular del Magistrado Eugeni Gay, partiendo de que las formas en democracia tienen una importancia que va más allá o trasciende de lo estrictamente necesario, cree que la argumentación que fundamenta la decisión mayoritaria debería haber analizado si la votación del Pleno de la Cámara que acuerda adoptar el procedimiento de lectura única observa o no el mandato normativo contenido en el artículo $150 \mathrm{RC}$, por cuanto no puede decirse a primera vista que la proposición tuviera un formulación simple, y su naturaleza parecía requerir una tramitación tal que facilitara la participación más plural posible, con la cual no se compadece el procedimiento el procedimiento de lectura única.

25 Véase GARCÍA-ESCUDERO MÁRQUEZ, P., El procedimiento legislativo ordinario en las Cortes Generales, CEPC, Madrid, 2006, págs. 106-107. 
blamos de aplicación transversal a los distintos procedimientos (aunque puede haber alguna excepción, en particular respecto del de lectura única). La combinación de los procedimientos de lectura única y urgencia se ha producido en la tramitación en el Congreso de la reciente reforma constitucional.

El procedimiento de urgencia es el procedimiento más característico y general de los abreviados. En efecto, el desconcentrado en comisión, que también puede ser contemplado desde el prisma de la abreviación de trámites, tiene limitadas por el artículo 75.3 de la Constitución las materias sobre las que puede recaer (excluyendo precisamente la reforma constitucional); y el procedimiento de lectura única, contrario al anterior en cuanto que el trámite que suprime es el de comisión (mientras que en aquél es el de Pleno), debe aplicarse sólo, al menos según los artículos 150 RC y 129 RS, a proyectos cuya naturaleza lo aconseje o su simplicidad de formulación lo permita.

La tramitación urgente cabe, por el contrario, para cualquier proyecto o proposición de ley. Se trata además de un procedimiento de abreviación estrictamente temporal, en cuanto actúa exclusivamente sobre los plazos establecidos con carácter general para reducirlos a la mitad, sin supresión ni modificación de trámites. Su sencillez hace, por tanto, que sea el procedimiento abreviado más utilizado. A diferencia del procedimiento de lectura única, el de urgencia tiene apoyatura constitucional, pues es mencionado dos veces en la Constitución, en los artículos 86.3 (tramitación de los decretos-leyes convalidados como proyectos de ley por el procedimiento de urgencia) y 90.2 (reducción del plazo de tramitación de los proyectos en el Senado) ${ }^{26}$.

Este procedimiento está configurado como procedimiento legislativo especial en el Reglamento del Senado (artículos 133-135), lo cual es lógico, dada la incidencia que, conforme al artículo 90.3 CE, tiene la declaración de urgencia sobre la tramitación de textos legislativos en el Senado, cuya duración queda reducida a veinte días naturales ${ }^{27}$. La regulación reglamentaria introduce una drástica reducción de los plazos a lo largo del procedimiento y su cómputo en días naturales, además de facultar a la Mesa para acordar modificaciones en aquéllos.

El Reglamento del Congreso de los Diputados regula la declaración de urgencia entre las disposiciones generales de procedimiento (Título IV, Capítulo sexto, arts. 93-94), como un procedimiento (así lo califica el artículo 93.2) aplicable a la tramitación de cualquier asunto.

26 Discrepamos, pues, de la afirmación de RUIZ ROBLEDO de que el procedimiento de urgencia haya sido creado por los Reglamentos, elemento de distinción que utiliza en apoyo de una clasificación tripartita (A. Ruiz Robledo, «Sobre los tipos de procedimientos legislativos», El procedimiento legislativo. V Jornadas de Derecho Parlamentario, Congreso de los Diputados, Madrid, 1997, pág. 661).

27 Aunque, como señala la STC 234/2000 (en el conflicto entre órganos constitucionales sobre la declaración de urgencia del Proyecto de Ley sobre interrupción voluntaria del embarazo), el enunciado del artículo 90.3 CE «pone de manifiesto que no constituye propiamente objeto del mismo la regulación de un procedimiento legislativo abreviado para la tramitación de proyectos normativos caracterizados por la urgencia», no existiendo en nuestro texto constitucional, a diferencia de otros, «un precepto que prevea el establecimiento de uno o varios procedimientos de tal carácter, por más que su completa regulación se remita a una norma de desarrollo». El Tribunal considera que el precepto citado se configura como uno de los varios preceptos constitucionales en los que se plasma la diferente posición que ocupan el Congreso de los Diputados y el Senado en el procedimiento legislativo ordinario, así como de las relaciones entre una y otra Cámara en el ejercicio de la potestad legislativa que el artículo 66.2 CE residencia en las Cortes Generales (FJ 8). 
La declaración de urgencia tiene como efecto la reducción a la mitad de los plazos establecidos con carácter ordinario. Ahora bien, de una parte, se salva la facultad reconocida a la Mesa de la Cámara en el artículo $91 \mathrm{RC}$ de acordar la prórroga o reducción de los plazos; de otra, la escasa fijación de plazos por el Reglamento para las distintas fases del procedimiento en el Congreso (apenas quince días para la presentación de enmiendas, quince días ampliables para la elaboración del informe de la ponencia y dos meses, asimismo ampliables y escasamente observados, para la tramitación de cualquier asunto por una comisión - artículo 43.2 RC-) hace que la tramitación de un proyecto o proposición en el Congreso no tenga una duración fija o media ${ }^{28}$. Por eso, la reducción a la mitad de los plazos tiene consecuencias muy relativas en esta Cámara, aunque sí puede servir a la mayoría de la Mesa para apoyar la eventual denegación de la ampliación del plazo de enmiendas o a la mayoría pura y simple para justificar su inclusión apresurada en el orden del día del Pleno ${ }^{29}$.

El artículo 91 RC permite a la Mesa de la Cámara (con carácter general no limitado a los procedimientos legislativos) la prórroga o reducción de los plazos establecidos por el Reglamento, disponiendo que salvo casos excepcionales las prórrogas no serán superiores a otro tanto del plazo ni las reducciones a su mitad.

En el procedimiento de reforma constitucional que nos ocupa, el plazo de presentación de enmiendas acordado por la Mesa del Congreso de los Diputados es de dos días, desde la toma en consideración (la sesión plenaria del día 30 de agosto concluye a las doce horas y cuarenta minutos del mediodía, según el Diario de Sesiones) hasta las catorce horas del jueves día 1 de septiembre, como anuncia el Presidente al término de la votación de aquella.

En los proyectos legislativos, las reducciones o prórrogas del plazo de enmiendas suelen estar causadas por el consenso de los grupos en cuanto a una tramitación acelerada de determinados proyectos ${ }^{30}$ o por haberse incluido el proyecto o proposición en el orden del día del Pleno de una sesión plenaria concreta (tal es el caso de las sesiones extraordinarias), que hace necesario adaptar la tramitación a dicha fecha.

La reforma constitucional podemos entender que entra plenamente en el segundo supuesto. Sabemos que no se aplica estrictamente la prescripción del artículo 99.2 RC,

28 Por poner un ejemplo de tramitación «urgentísima» para otra época, citado por DELGADO-IRIBARREN GARCÍA-CAMPERO, M., («Crónica parlamentaria del Congreso de los Diputados», septiembre de 1984-junio de 1985», Revista de las Cortes Generales, nº 6, 1985, pág. 311): la del Proyecto de L.O. de autorización para la adhesión de España a las Comunidades Europeas (luego Ley Orgánica 10/1985, de 2 de agosto), fue solventada en veinte días, aunque las fases de ponencia, comisión y Pleno se agotaron en el mismo día, el siguiente al del debate de totalidad. En realidad, la tramitación duró algo más de un mes, de 14 de junio a 17 de julio de 2005.

29 Frente al señalado efecto drástico que la declaración de urgencia tiene en el Senado respecto de los textos legislativos — que no es de aplicación a la reforma constitucional—, cuyo plazo de tramitación se reduce por disposición del artículo 90.3 de la Constitución de dos meses a veinte días naturales.

30 Así, el plazo de enmiendas a la Proposición de Ley, presentada por todos los grupos parlamentarios, de solidaridad con las víctimas del terrorismo (tomada en consideración por el Pleno del Congreso el 14 de septiembre de 1999 y acordada a continuación su tramitación por lectura única), tuvo una duración de un día, hasta el día 15 a las veinte horas, incluyéndose su debate en el orden del día del Pleno el 16 de septiembre, con lo que concluyó su tramitación en esta Cámara en tres días (véanse Diario de Sesiones núm. 255, de 14 de septiembre de 1999, pág. 13516, y BOCG Congreso, Serie B, núm. 321-2, de 15 de septiembre de 1999). 
según el cual, salvo en casos excepcionales, las prórrogas no serán superiores a otro tanto del plazo ni las reducciones a su mitad, siendo la oportunidad política la que determina la duración de la ampliación o la reducción. Lo que ya no es tan justificable, tratándose de una reforma constitucional, aunque sí comprensible por las premuras impuestas por compromisos políticos supranacionales, es que el plazo de ocho días previsto para la presentación de enmiendas en caso de declaración de urgencia - frente a los quince del procedimiento ordinario - se reduzca a dos días en este caso.

También los recurrentes en amparo ante el Tribunal Constitucional han cuestionado la tramitación urgente y la consiguiente reducción del plazo de enmiendas, y nuevamente el Tribunal entiende que la Mesa se ha ajustado al Reglamento (FJ 4), sin necesidad de que motivara su decisión, la cual por otra parte considera que se apoyaba en razones de fondo, como el anuncio público del término de la legislatura y las consiguientes razones de excepcionalidad que habilitaban a la Mesa para reducir el plazo de presentación de enmiendas. Entiende asimismo que, aun en términos perentorios, la tramitación urgente no ha impedido a los recurrentes las facultades que les corresponden como diputados en el seno del procedimiento legislativo, citando como prueba el que hayan presentado una extensa enmienda de totalidad y apoyándose en la doctrina contenida en la STC 234/2000.

\section{b) Senado}

Cabría pensar que el deseo de ser más respetuosos con la exigencia reglamentaria de que el procedimiento especial de lectura única se aplique a un proyecto o proposición cuya naturaleza lo aconseje o su simplicidad de formulación lo permita fuera la razón que ha llevado a prescindir de este procedimiento en la Cámara alta para la tramitación de la Proposición de reforma del artículo 135 de la Constitución, en aras de la posibilidad de modificación del texto. $\mathrm{O}$, tal vez, la exclusión podía estar motivada por la prohibición de presentar enmiendas al articulado en el procedimiento de lectura única, contenida en el artículo 129.3 del Reglamento del Senado, que impedía otorgar un margen a la negociación, aunque sólo fuera formalmente. $\mathrm{O}$, más sencillamente, la razón podía ser la mayor rapidez que ofrece el procedimiento ordinario en esta Cámara, puesto que la constitución de ponencia es facultativa (110 RS), frente a la dificultad de convocar dos reuniones plenarias, una de ellas en fin de semana.

En realidad, la exclusión del procedimiento especial de lectura única en el Senado, en ésta como en la anterior reforma constitucional, viene impuesta por el artículo 154 RS, con el que se abre el capítulo relativo a la revisión constitucional iniciada por el Congreso de los Diputados:

— el artículo 154.1 establece como primer trámite que «la Mesa dispondrá su inmediata publicación y fijará el plazo para la presentación de enmiendas», lo que parece excluir un procedimiento en el que no cabe presentar más que propuestas de veto, como es el de lectura única.

- el apartado 2 de este mismo artículo regula la actuación de la Comisión de Constitución, que podrá designar una ponencia y elaborará el dictamen que será elevado al Pleno de la Cámara para su debate y votación en los plazos que se fijen por la Presidencia, de acuerdo con la Mesa y oída la Junta de Portavoces. 
En conclusión, si el artículo 154 prevé la presentación de enmiendas y la intervención de la Comisión, el procedimiento de lectura única no puede aplicarse a las reformas constitucionales.

No por ello la tramitación se ha desarrollado de forma más sosegada que en el Congreso: la Mesa del Senado aprueba un calendario en el que el plazo de enmiendas se abre de sábado a lunes (desde la publicación el 3 de septiembre hasta el lunes 5 de septiembre a las 20 horas), no se prevé la formación de ponencia, la Comisión se reúne el martes día 6 a las 13 horas y el Pleno el día 7 . En suma, cinco días para una reforma de la Constitución.

\section{c) Conclusión: tramitación impropia de una reforma constitucional}

Decía hace unos años en una obra dedicada al procedimiento legislativo, al excluir de los procedimientos legislativos especiales el de reforma constitucional: «Aunque la regulación que los reglamentos contengan [de la reforma constitucional] haya de remitirse por fuerza al procedimiento legislativo, estableciendo las especialidades necesariamente derivadas de la regulación contenida en los artículos 166 a 169 de la Constitución, ello no obsta a que no se trate de un procedimiento legislativo especial, sino del procedimiento de tramitación de una reforma constitucional, norma diferente a la ley» ${ }^{31}$. La Constitución es la ley de leyes o norma normarum, su posición en el ordenamiento jurídico merecía un tratamiento especial, distinto del aplicado a las leyes resultantes de compromisos de última hora ${ }^{32}$.

De otra parte, los procedimientos elegidos y la premura en la tramitación han perjudicado, no ya la reflexión sobre el texto aprobado — que también-, sino la posibilidad de negociación sobre el mismo: véase la imposibilidad de tramitar unas enmiendas transaccionales queridas por los dos grupos mayores en el Pleno del Congreso, merced a unos preceptos reglamentarios que protegen a las minorías parlamentarias.

Sabido es que la política manda. Tanto más en este caso en que las urgencias proceden de «la actual situación económica y financiera, marcada por una profunda y prolongada crisis», como apunta el preámbulo de la reforma aprobada. Pero las prisas nunca son buenas, y el respeto a las formas es especialmente importante en una materia como la reforma de la Constitución. Dicho con las palabras del profesor De Esteban: «una reforma chapucera, pero necesaria». ${ }^{33}$

31 GARCÍA-ESCUDERO MÁRQUEZ, P., El procedimiento legislativo ordinario en las Cortes Generales, cit., pág. 103.

32 Estas reflexionan no afectan a que de lege lata las normas aplicables sean las del procedimiento legislativo, como afirma el Tribunal Constitucional en el Auto 9/2012. A este respecto, el Magistrado Ortega Alvarez, en un breve voto particular, considera que el Tribunal podría haber establecido el criterio de la necesidad de distinción entre los procedimientos legislativos, en los que las Cortes actúan como órganos y poderes constituidos, y los procedimientos parlamentarios de reforma constitucional, en los que actúan como poder constituyente. Sin corresponder al Tribunal establecer los términos concretos de dicha diferencia de procedimiento parlamentario, sí hubiera sido posible, a su juicio, el declarar la necesidad de establecer tal diferencia en respeto de la diferente condición de las Cortes Generales cuando actúan como órgano constituido a cuando lo hacen como órgano constituyente.

33 DE ESTEBAN, J., «Una reforma chapucera, pero necesaria», El Mundo, 24 de agosto de 2011. 


\section{LA INADMISIÓN DE ENMIENDAS}

Dedicamos especial atención al trámite de enmiendas — en el que las Mesas de ambas Cámaras inadmitieron algunas de las presentadas - por la relevancia que ha alcanzado esta inadmisión en los debates parlamentarios, invocándose incluso como motivo por distintos grupos parlamentarios para ausentarse o no participar en las votaciones.

\section{A. En el Congreso de los Diputados}

1. Enmiendas presentadas ${ }^{34}$

En el plazo abierto en el Congreso de los Diputados tras la toma en consideración de la Proposición de reforma del artículo 135 de la Constitución el 30 de agosto de 2011 hasta dos días después, el 1 de septiembre a las 14 horas, se presentaron 22 enmiendas de los Grupos siguientes:

a) Grupo Mixto

a.1 Sra. Fernández Davila y Sr. Jorquera Caselas (BNG)

- Enmienda ${ }^{\circ} 1$, de texto alternativo, que afectaba a los artículos 131 y 133 de la Constitución.

a.2 Sra. Barkos Berruezo (Nafarroa Bai), enmiendas $n^{\circ} 2$ y 3

— Enmienda ${ }^{\circ} 2$, de adición a la disposición adicional segunda nueva del texto siguiente: «Todo lo previsto en este artículo, sin perjuicio de las competencias que en esta materia corresponden a las Haciendas Forales de Navarra, Álava, Gipuzkoa y Bizkaia».

- Enmienda $\mathrm{n}^{\circ}$ 3, de adición a la disposición transitoria primera del texto siguiente: «La reforma contemplada en esta ley habrá de ser sancionada en referéndum, a celebrar el próximo 20 de noviembre de 2011, en coincidencia con la convocatoria de elecciones generales».

a. 3 Sra. Oramas y Sr. Ríos Rull (Coalición Canaria), enmiendas no 8 y 9

- Enmienda ${ }^{\circ} 8$, de modificación de los apartados 4 y 5 del artículo 135, en la redacción dada por la Proposición.

- Enmienda $n^{\circ}$ 9, de modificación de la disposición adicional $3^{\mathrm{a}}$ [de la Constitución] para definir «el modelo singular de encaje de Canarias en el Estado español».

a.4 Sra. Díez González (UPyD), enmiendas nº 20 a 24.

- Enmienda ${ }^{\circ} 20$, que propone como texto del artículo 135 el actual de la Constitución, por entender que la propia «Constitución española, nuestro ordenamiento jurídico, el Tratado de Maastricht y el Pacto de Estabilidad y Crecimiento son instrumentos suficientes para garantizar la estabilidad presupuestaria y controlar el déficit y la deuda pública».

34 Las enmiendas presentadas, el acuerdo de la Mesa de admisión o inadmisión a trámite y los escritos de reformulación se publican en el BOCG Congreso n 329-3, de 5 de septiembre de 2011. 
— Enmienda $\mathrm{n}^{\circ} 21$, de adición de una nueva disposición adicional primera con el texto siguiente: «Primera. La presente reforma constitucional será sometida a referéndum para su ratificación».

- Enmienda $n^{\circ} 22$, de adición de una nueva disposición adicional segunda con el texto siguiente: «En el plazo de seis meses desde la entrada en vigor de la presente ley el Gobierno presentará a las Cortes Generales un Proyecto de Ley de Reforma Constitucional que, con la finalidad de adecuar la Constitución a las necesidades del siglo XXI, abordará al menos las siguientes cuestiones básicas: régimen electoral, estructura territorial y competencial del Estado, e independencia del poder judicial. Con este fin la reforma perseguirá los siguientes objetivos: (...)».

- Enmienda ${ }^{\circ} 23$, de supresión de la disposición adicional única.

— Enmienda $n^{\circ} 24$, de modificación del artículo 167.3 de la Constitución, con el texto siguiente: «Aprobada la reforma por las Cortes Generales, será sometida a referéndum para su ratificación cuando el texto aprobado incluyese dicha previsión, o bien cuando lo soliciten, dentro de los quince días siguientes a su aprobación, una décima parte de los miembros de cualquiera de las Cámaras».

b) Grupo ERC-IU-ICV, enmiendas n ${ }^{\circ} 4$ a 7.

- Enmienda ${ }^{\circ} 4$, de texto alternativo ${ }^{35}$, que postula la aprobación de un principio de reforma de distintos artículos de la Constitución, al amparo del artículo 168 de la misma.

— Enmienda ${ }^{\circ} 5$, de supresión del artículo único de la proposición (lo que equivale a una enmienda a la totalidad de devolución).

- Enmienda $n^{\circ}$ 6, de adición de una nueva disposición adicional de modificación del artículo 2 de la Constitución con el texto siguiente: «La Constitución reconoce y garantiza el derecho a la autonomía de las naciones y regiones que integran el estado y la solidaridad entre todas ellas». Y de adición de una nueva disposición adicional al texto constitucional con el texto siguiente: «La

35 La enmienda de texto alternativo se fundamenta «en razones de forma y procedimiento y en razones de fondo». En cuanto a las primeras se afirma: «Un Estado social y democrático de derecho, cuya soberanía popular reside en el pueblo, tal y como se afirma en el primero de los artículos de la Constitución Española, y el establecimiento de una democracia avanzada, tal y como proclama el Preámbulo de nuestra Constitución, es absolutamente contradictorio con un procedimiento de reforma constitucional como el pactado y decidido por los Grupos parlamentarios PSOE y PP.// La declaración de situación de excepcionalidad para la reducción de los plazos parlamentarios al mínimo imprescindible, la aprobación del mecanismo de lectura única que evita un trabajo serio, una negociación real en búsqueda de consensos y un contraste con expertos, con la sociedad y con los órganos competentes, y el intento de evitar que el pueblo pueda pronunciarse a través de un referéndum vinculante son razones de forma que afectan de manera radical al fondo.// El procedimiento elegido por los Grupos parlamentarios PSOE-PP convierte en ilegítimo y probablemente en inconstitucional el resultado que se produciría si finalmente es aprobada la reforma constitucional en estas condiciones». Entre las modificaciones recogidas en los apartados $\mathrm{A}$ a $\mathrm{K}$ del artículo único, cabe reseñar el apartado $\mathrm{H}$, según el cual «se reformará el artículo 2 y el Título VIII para permitir la definición de nuestro Estado como un Estado Federal, con reconocimiento de la plurinacionalidad y la capacidad de autogobierno de las diferentes realidades territoriales», y el apartado J: «Se abordará la forma política del Estado, permitiendo la opción, independiente de las demás reformas, entre la monarquía hereditaria o el modelo republicano, lo que afectaría al artículo 1.3, al Título II y a todos aquellos artículos que hacen referencia a las funciones del Rey». 
Constitución reconoce el derecho del pueblo catalán a la autodeterminación. Este derecho reside en la potestad de sus ciudadanos para decidir libre y democráticamente su estatus político, económico, social y cultural, bien dotándose de un marco propio o compartiendo, en todo o en parte, su soberanía con otros pueblos.// Serán, en su caso, sus instituciones respectivas, gobierno y parlamento, las únicas legitimadas para impulsar su ejercicio» ${ }^{36}$.

— Enmienda $\mathrm{n}^{\mathrm{a}} 7$, de adición «a la nueva disposición» del texto siguiente: «En cuanto a la financiación de la Generalitat de Catalunya se establecerá un régimen fiscal de concierto económico. Anualmente se acordará el cupo que como contribución a todas las cargas del Estado que no asuma la Generalitat o como financiación a las cargas generales del Estado que deberá satisfacer la misma».

c) Grupo Parlamentario Vasco (EAJ-PNV), enmiendas n. ${ }^{\circ} 10$ y 11.

- Enmienda ${ }^{\circ} 10$, de modificación de los puntos 2 y 3 del artículo 135 en el texto de la proposición, para incluir la referencia a los territorios forales.

- Enmienda $\mathrm{n}^{\mathrm{a}} 11$, de adición de una nueva disposición adicional segunda de modificación del artículo 2 y de adición de una nueva disposición adicional a la Constitución, en los mismos términos que la enmienda n 6 de ERC-IU-ICV.

d) Grupo Catalán (CiU), enmiendas n. ${ }^{\circ} 12$ a 19.

- Enmienda $\mathrm{n}^{\circ} 12$, de supresión del párrafo 2 del apartado 2 del artículo 135, proponiendo que todo lo que debe ser regulado por ley orgánica se integre en el apartado 5.

- Enmienda n ${ }^{\circ} 13$, de modificación del apartado 3 para precisar que la autorización para emitir deuda pública o contraer crédito, en el caso de las Comunidades Autónomas, corresponderá a los respectivos órganos legislativos.

- Enmienda $\mathrm{n}^{\circ} 14$, de modificación del apartado 4 del artículo 125, introduciendo la apreciación por el legislativo autonómico para la superación del límite de deuda estructural por las Comunidades Autónomas en situaciones excepcionales.

- Enmienda $\mathrm{n}^{\circ} 15$, de modificación del apartado 5 del artículo 135, sistematizando en su contenido lo que debe ser regulado por ley orgánica y limitando al Estado algunas de las previsiones.

- Enmienda $\mathrm{n}^{\circ}$ 16, de adición de una nueva letra al apartado 5 del artículo 135, para que la ley orgánica de desarrollo regule también los límites de déficit fiscal territorial estructural de cada Comunidad autónoma en el conjunto del Estado.

- Enmienda $n^{\circ} 17$, de modificación del apartado 6 del artículo 135, atribuyendo a las Comunidades Autónomas la aprobación por ley de su respectivo límite máximo estructural.

- Enmienda $\mathrm{n}^{\mathrm{a}}$ 18, de conversión de la disposición adicional única en transitoria única (lo que, dicho sea de paso, habría sido técnicamente más correcto), dado su contenido, con la excepción del apartado 2, referido al contenido de la ley orgánica.

36 Esta enmienda se fundamenta, como justificación, en declaraciones del Parlamento de Cataluña y en el hecho de que la «sentencia del Estatut de Catalunya ha supuesto un auténtico "golpe de Estado constitucional"». 
- Enmienda $\mathrm{n}^{\circ} 19$, para suprimir el apartado 2 de la disposición adicional única, cuyo contenido se integraría en el apartado 135.5.

\section{Enmiendas inadmitidas por la Mesa del Congreso}

La Mesa del Congreso de los Diputados, en su reunión del día 1 de septiembre de 2011, inadmite varias enmiendas por distintas razones que podemos clasificar a continuación:

a) Enmiendas que pretendían que la reforma fuera sometida a referéndum. Se inadmiten «por suponer una alteración del procedimiento de reforma constitucional contemplado en el Título X de la Constitución»:

- Disposición final única incluida en la enmienda $n^{\circ} 1$ del Grupo Mixto (Sra. Fernández Dávila y Sr. Jorquera Casales).

- Enmienda $n^{\circ} 3$ de la Sra. Barkos (Grupo Mixto)

- Enmienda no 21 de la Sra. Diez (Grupo Mixto)

b) Enmiendas que pretendían la reforma de preceptos de la Constitución para los que el artículo 168 exige procedimiento agravado ${ }^{37}$ :

- Enmienda $n^{\circ} 4$ del Grupo ERC-IU-ICV, «en la medida en que postula una reforma al amparo del artículo 168 de la Constitución» ${ }^{38}$.

- Enmienda $n^{\circ} 6$ del Grupo ERC-IU-ICV, que pretendía la reforma del artículo 2 y añadir una nueva disposición adicional, «en la medida en que postula una reforma de un artículo del Título Preliminar para cuya reforma el artículo 168 exige un procedimiento agravado».

— Enmienda $n^{\circ} 11$ del Grupo Vasco (EAJ-PNV), que pretendía (proponiendo la adición de una nueva disposición adicional segunda, aunque en realidad lo pre-

37 El recurso de amparo presentado por dos diputados de IU impugnaba que, inicialmente, la Mesa hubiera calificado la Proposición de reforma constitucional dentro de los supuestos objeto del procedimiento ordinario de reforma contemplados en el art. $167 \mathrm{CE}$, sobre la base de que la misma supone una reforma encubierta del Título Preliminar de la Constitución, afecta a distintos derechos fundamentales en cuanto merma su nivel de protección y menoscaba, en fin, las facultades de los diputados y de los propios ciudadanos. El Tribunal Constitucional entiende que la Mesa actuó correctamente por cuanto «el texto constitucional establece de manera precisa la finalidad de las dos vías de reforma que prevé, en función de los objetos sobre los que se puede proyectar, de tal modo que admitir la pretensión de los recurrentes alteraría el equilibrio buscado por el constituyente, corriendo el riesgo de dejar a la discreción del órgano rector de la Cámara la determinación del procedimiento de reforma constitucional» (FJ 2).

38 En efecto, la justificación de la propia enmienda, que se presenta como texto alternativo a la Proposición de reforma, señala que «el proceso para la aprobación de la reforma contenida en la enmienda a la totalidad es el determinado por el artículo 168 de la Constitución, toda vez que las materias que han de ser objeto de reforma afectan a los derechos y deberes fundamentales de las personas que habitan en nuestro país.// En consecuencia, se incluyen en esta iniciativa las líneas que han de regir la reforma constitucional al objeto de que, tal y como determina el artículo 168.1 de la Carta Magna, una vez aprobados los principios de la reforma, se proceda a la disolución inmediata de las Cortes para que sean las nuevas Cámaras electas las que estudien el nuevo texto constitucional y, tras su aprobación, proceda a someterla a referéndum popular vinculante».

La inadmisión de esta enmienda fue recurrida en amparo, habiéndonos ocupado ya de distintos aspectos contemplados por el Auto 9/2012. En cuanto a la doctrina sobre este punto, véase infra, apartado C, al tratar de los motivos de inadmisión. 
tendido debería haber formado parte del articulado de la proposición de reforma, que contiene la parte que se inserta en el texto de la Constitución) la modificación del artículo 2 y la adición de una nueva disposición adicional al texto constitucional. La inadmisión a trámite se realiza en los mismos términos que para la enmienda $n^{\circ} 6$.

c) Enmienda cuyo contenido material es de enmienda a la totalidad de devolución, enmiendas no admisibles, conforme al artículo 126.5 del Reglamento del Congreso (al que se remite el 146.1) respecto de las proposiciones previamente tomadas en consideración por la Cámara:

- Enmienda $n^{\circ} 5$ del Grupo ERC-IU-ICV, de supresión del artículo único de la Proposición de reforma.

Los Grupos parlamentarios proponentes presentaron sendas solicitudes de reconsideración de la inadmisión de las enmiendas no 4 (ERC-IU-ICV) y 21 (Sra. Diez, Grupo Mixto), solicitudes que fueron desestimadas por la Mesa en su reunión de 2 de septiembre de 2011.

Los Grupos Parlamentarios Vasco (EAJ-PNV) y ERC-IU-ICV presentaron sendos escritos de reformulación, «a efectos de clarificar» sus enmiendas $\mathrm{n}^{\circ} 11$ y 6 , respectivamente. La Mesa acordó comunicar a los autores que estas enmiendas habían sido inadmitidas por postular una reforma de un artículo del Título Preliminar para cuya reforma el artículo 168 exige un procedimiento agravado, «sin que proceda su reformulación en esta fase, sino reiterar el acuerdo adoptado por la Mesa».

3. Enmiendas respecto de las que se solicita reformulación o aclaración

a) Enmiendas respecto de las que se solicita reformulación del texto propuesto «en la medida en que, al no formar parte del articulado de la reforma, el texto no es idóneo para alcanzar el objetivo perseguido».

Dicho de otra manera, son las modificaciones de la Constitución incluidas en el articulado de la proposición las que se incorporan al texto constitucional, no así las disposiciones adicionales, transitorias, derogatorias o finales que pueda contener la proposición de reforma.

- De la enmienda $n^{\circ} 1$ del Grupo Mixto (Sra. Fernández Davila y Sr. Jorquera) — de texto alternativo- el texto propuesto de la disposición adicional única, con el tenor siguiente: «La integración o adhesión del Estado español a organizaciones internacionales, así como la suscripción de Tratados internacionales o cualesquiera otros instrumentos legales que impliquen la cesión de facultades en la dirección y planificación de la economía, la política fiscal o monetaria estará supeditada a mantener de forma inalterable los principios de planificación económica y política fiscal y tributaria contenidos en la Constitución y las leyes que la desarrollen».

Esta enmienda fue objeto de reformulación por sus proponentes, sustituyendo la referencia a la disposición adicional única por un punto Tres en el artículo único, de modificación del artículo 93 de la Constitución. 
— Enmienda n ${ }^{\circ}$ 2, del Grupo Mixto (Sra. Barkos), que pretendía la adición de una disposición adicional segunda nueva salvando las competencias de las Haciendas forales.

Esta enmienda fue objeto de reformulación por su proponente, como propuesta de adición de un punto 7 al artículo 135 .

— Enmienda $n^{\circ} 7$ del Grupo ERC-IU-ICV, formulada como de adición «a la nueva disposición» del texto antes transcrito de establecimiento de un régimen fiscal de concierto económico para la financiación de Cataluña.

Esta enmienda fue objeto de reformulación por su proponente, convirtiéndola en propuesta de adición de un artículo 2 a la proposición de reforma con el texto de la enmienda.

b) Se solicita aclaración respecto de la enmienda $\mathrm{n}^{\circ} 22$ del Grupo Mixto (Sra. Díez), en cuanto al encaje que la disposición propuesta en la misma tendría en el texto de la proposición de reforma. La enmienda se formulaba como «de adición. Nueva disposición adicional segunda».

Esta enmienda fue objeto de reformulación, indicando que la pretensión de la misma era incorporar esta nueva disposición adicional segunda al texto de la proposición.

c) Motivos para la exigencia de reformulación o aclaración.

Como se ha señalado, tanto en los casos en que la Mesa del Congreso solicita reformulación como en el que solicita aclaración de las enmiendas presentadas, los motivos para no admitirlas directamente son formales, de técnica legislativa, por no haberse formulado correctamente las enmiendas que pretendían la modificación de preceptos constitucionales. Al no insertarse estas propuestas en el articulado del texto de la proposición de reforma, no se produciría el efecto pretendido de modificación de la Constitución.

Una vez corregidos estos defectos formales, las enmiendas fueron admitidas por la Mesa del Congreso en los términos de la reformulación o aclaración.

\section{B) En el SEnado}

1. Enmiendas presentadas

En el Senado se presentaron 29 enmiendas:

a) Grupo Mixto, Sr. Quintero Castañedas, enmiendas $n^{\circ} 13$ y 14, similares a las presentadas por Coalición Canaria (Grupo Mixto) en el Congreso.

b) Grupo Entesa Catalana de Progrès, enmiendas no 1 a 12 y 15 a 17.

— Enmiendas 1 a 3, de supresión de los párrafos 4 y 5 de la Exposición de Motivos, respectivamente.

— Enmiendas $n^{\circ} 3$ y 4, de supresión del artículo único

— Enmienda $n^{\circ} 5$, de modificación de la disposición adicional única para incluir la reforma del artículo 2 de la Constitución. 
— Enmienda $\mathrm{n}^{\circ}$ 6, de modificación de la disposición adicional única para añadir una nueva disposición adicional al texto constitucional en la que se reconoce el derecho del pueblo catalán a la autodeterminación.

- Enmienda $n^{\circ} 7$, de modificación de la disposición adicional única para añadir una nueva disposición adicional al texto constitucional estableciendo el régimen fiscal de concierto económico para la financiación de la Generalitat de Catalunya, en términos similares a la enmienda $\mathrm{n}^{\circ} 7$ presentada por ERC-IU-ICV en el Congreso.

— Enmiendas $n^{\circ} 8,9$ y 10, de supresión de la disposición adicional única, puntos 1, 2 y 3 , respectivamente.

- Enmiendas $\mathrm{n}^{\circ} 11$ y 16, de modificación de la disposición final única para supeditar la entrada en vigor a la aprobación por referéndum y para incluir en la Exposición de Motivos la referencia a la necesidad de convocatoria de referéndum en este tipo de reformas de fuerte impacto económico y social y que generan un fuerte debate en la sociedad española.

- Enmienda $n^{\circ} 12$, de supresión de la disposición final única.

- Enmienda $n^{\circ} 15$, de supresión del tercer párrafo de la Exposición de Motivos.

- Enmienda ${ }^{\circ} 17$, de modificación de la disposición final única, para incluir la referencia a la posibilidad de solicitud de un referéndum por una décima parte de los miembros de cualquiera de las Cámaras.

c) Grupo Parlamentario de Senadores Nacionalistas, enmiendas $n^{\circ} 18$ a 21.

- Enmiendas n 18 y 19, para incluir la referencia a los territorios forales en los apartados 2 y 3 del artículo 125.

- Enmienda n ${ }^{\circ} 20$, de supresión del artículo único.

- Enmienda $n^{\circ} 21$, de adición de una nueva disposición adicional al texto constitucional en el que se reconoce el derecho del pueblo vasco a la autodeterminación en términos casi idénticos a la enmienda $\mathrm{n}^{\circ} 6$ de Entesa.

d) Grupo Parlamentario Catalán en el Senado de Convergencia i Uniò, enmiendas $\mathrm{n}^{\circ} 22$ a 29 .

- Enmiendas $n^{\circ} 22$ y 23, para introducir al órgano legislativo autonómico en los apartados 3 y 4 del artículo 135, en términos similares a las presentadas con los números 13 y 14 por el Grupo Catalán-CiU en el Congreso.

- Enmienda ${ }^{\circ}$ 24, de modificación del apartado 5 del artículo 135, sistematizando en su contenido lo que debe ser regulado por ley orgánica y limitando al Estado algunas de las previsiones, en términos similares a la enmienda $\mathrm{n}^{\circ} 15$ presentada en el Congreso.

— Enmienda $\mathrm{n}^{\circ} 25$, de modificación del apartado 6 en términos similares a la enmienda $n^{\circ} 17$ presentada en el Congreso.

— Enmienda no 26, de supresión del apartado 2 del artículo 135.

- Enmienda ${ }^{\circ} 27$, de adición de una nueva letra al apartado 5, en términos similares a la enmienda $n^{\circ} 16$ presentada en el Congreso.

- Enmienda $n^{\circ} 28$, de modificación del título de la disposición adicional única, que pasa a ser disposición transitoria. 
— Enmienda $\mathrm{n}^{\circ} 29$, de supresión del punto 2 de la disposición adicional única, cuyo contenido se integraría en el nuevo apartado 5.

2. Enmiendas inadmitidas por la Mesa del Senado

La Mesa del Senado, en su reunión del día 6 de septiembre de 2011, acordó no admitir a trámite las siguientes enmiendas:

a) Enmienda inadmitida por estar repetida su formulación en otra enmienda:

- Enmienda $n^{\circ} 4$, del Grupo Entesa. Las enmiendas no 3 y 4 eran iguales, de supresión del artículo único, diferenciándose únicamente en la justificación. Se admite la primera presentada.

b) Enmiendas inadmitidas por postular una reforma para la que se exige la aplicación del artículo168 de la Constitución.

- Enmienda $n^{\circ} 5$, de Entesa, de modificación del artículo 2 (mal redactada técnicamente por contemplarla como modificación de la disposición adicional de la proposición), incluido en el Título Preliminar de la Constitución.

- Enmiendas $n^{\circ}$ 6, de Entesa, y n 21 de Senadores Nacionalistas, que pretendan añadir una disposición adicional a la Constitución reconociendo el derecho de autodeterminación de Cataluña y País Vasco, respectivamente. La inadmisión se hace «en la medida en que postula(n) una reforma que exige la aplicación del artículo 168 de la Constitución», es de suponer que porque materialmente la reforma afecta al artículo 2 de la misma.

c) Enmienda inadmitida que supeditaba la entrada en vigor de la reforma a la celebración de referéndum:

- Enmienda $n^{\circ} 11$, de Entesa, «por suponer una alteración del procedimiento de reforma constitucional contemplado en el Título X de la Constitución».

\section{C) Examen de los motivos de inAdmisión. Límites al DeReChO DE ENMIENDA EN LA REFORMA CONSTITUCIONAL}

Llegados a este punto, podemos intentar contemplar la inadmisión de enmiendas a la Proposición de reforma del artículo 135 de la Constitución a la luz de los límites al derecho de enmienda que poseen diputados y senadores.

1. Significado del derecho de enmienda

El derecho de enmienda, o de modificación de las iniciativas legislativas, implica la facultad de la Cámara de ejercer en plenitud su poder legislativo ${ }^{39}$, mediante la intro-

39 El que puede lo más, puede lo menos; por eso, dice E. SPAGNA MUSSO, el poder de enmienda está comprendido en el poder de iniciativa legislativa [L iniziativa nella formazione delle leggi italiane, vol.1 («Il potere di iniziativa legislativa»), Jovene, Nápoles, 1958, pág. 150]. 
ducción de modificaciones en los textos que tramita, para obtener en el producto final del procedimiento (la ley en el procedimiento legislativo, la reforma constitucional en el caso que nos ocupa) los dos objetivos que éste persigue: la mayor perfección técnica posible y el más amplio consenso de voluntades.

De otra parte, el principio de libertad de deliberación de las Cámaras exige el reconocimiento del también llamado derecho de enmienda - pero que en este caso sólo es de propuesta de modificación - a sus miembros o a los grupos parlamentarios que éstos forman ${ }^{40}$. Como explica Biglino Campos ${ }^{41}$, para los miembros de la minoría la enmienda constituye la posibilidad de introducir cambios en los textos legislativos, de manera que les sea posible votar a su favor, a la vez que es un instrumento para el ejercicio de la función de oposición, ya que permiten dar publicidad y contraponer las propias concepciones a las de la mayoría y el Gobierno. Para la mayoría, sería el medio esencial para intervenir en el procedimiento legislativo y contrapesar de alguna forma el protagonismo desempeñado por el Gobierno mediante la presentación de proyectos de ley.

Entendemos por enmienda, a la vez, la modificación y la propuesta de modificación de un texto que está siendo tramitado por las Cámaras. La doctrina parte en ocasiones de la configuración del derecho de enmienda del Parlamento como iniciativa legislativa secundaria $^{42}$, derivada ${ }^{43}$, incidental ${ }^{44}$, frente a la originaria, ejercida mediante la presentación de textos legislativos independientes. Sin embargo, se trata de instituciones de naturaleza diferente, fundamentado como está el derecho de enmienda en garantizar que la actividad legislativa se desenvuelva de forma que permita examinar plenamente los intereses opuestos sobre la cuestión objeto de aquella.

Por más que se asemejen las enmiendas a la iniciativa legislativa, aunque sea disminuida, en el sentido de que ambas pretenden someter a la consideración de la Cámara un texto sobre el que aquélla ha de deliberar y resolver, aceptándolo o rechazándolo en todo o en parte, la similitud es de orden lógico, pero su fundamento es diverso ${ }^{45}$. De ahí

40 Como señala E. SPAGNA MUSSO, lo que comúnmente se conoce como enmiendas, no son sino propuestas de enmiendas; la enmienda al texto se produce cuando aquélla sea aprobada por la Cámara, no antes. De modo que el poder de enmienda pertenece en exclusiva a las Cámaras (L'iniziativa nella formazione delle leggi italiane, cit., pág. 151). Sin embargo, no considera a las enmiendas de totalidad con texto alternativo verdaderas enmiendas, sino actos de iniciativa legislativa concurrente («Emendamento», Enciclopedia del Diritto, t. XIV, Giuffrè, Milán, 1965. pág. 829).

41 BIGLINO CAMPOS, P., «Enmienda en el procedimiento legislativo», cit., pág. 2803.

42 MICELI, V., L’iniziativa parlamentare, Milán, 1903, pág. 266.

43 SANTAOLALLA LÓPEZ, F., «Iniciativa legislativa parlamentaria: problemática de las enmiendas», El procedimiento legislativo. V Jornadas de Derecho Parlamentario, Congreso de los Diputados, Madrid, 1997, pág. 237.

44 MERINO MERCHÁN, J.F., DE LA PEÑA RODRÍGUEZ, L., «Las facultades de calificación de las enmiendas por las Mesas de las Cámaras», Revista de las Cortes Generales, nº 23, 1991, pág. 138.

45 SPAGNA MUSSO, S., L'iniziativa nella formazione delle leggi italiane, cit., págs. 160-161. No puede hablarse de identificación ni de paralelismo entre ambas categorías, sino sólo de parcial convergencia de finalidad, en cuanto que también la propuesta de enmienda tiende a realizar una selección (aunque sea limitada) de los intereses que se someten a la regulación legislativa, en adición o en sustitución de parte de los intereses previstos en el proyecto de ley («Emendamento», cit., pág. 829). Para E. PIERRE (Traité de droit politique, électoral et parlementaire, $4^{a}$ ed., Librairies et Imprimeries Réunies, París, 1893, pág. 843) el derecho de enmienda se presenta como el corolario del derecho de iniciativa, aunque se trate de una iniciativa limitada, por cuanto no puede hacer nacer una cuestión nueva. No obstante, señalan AVRIL, P., y GICQUEL, J., (Droit parlementaire, Montchrestien, París, 1988, pág. 152), la relación con el texto debatido es una cuestión de admisibilidad que depende de la apreciación del legislador, el cual siempre puede ampliar las cuestiones iniciales. 
que existan diferencias sustanciales. Pueden señalarse como caracteres específicos de las enmiendas su carácter subordinado con respecto del proyecto o proposición al que se formulan, de forma que carecen de vida independiente o no existen sin una previa iniciativa legislativa, y su carácter puntual, frente a la generalidad del proyecto o proposición de ley (con la salvedad de las enmiendas a la totalidad de texto alternativo) ${ }^{46}$. La enmienda es el instrumento para complementar (mediante la adición o supresión) o modificar (enmiendas de sustitución) las iniciativas presentadas.

La legitimación para la presentación de enmiendas está reconocida en nuestros Reglamentos parlamentarios a los miembros de las Cámaras y a los grupos parlamentarios. Esta facultad, junto con la presentación de preguntas, sería el último reducto de labor individual que se reconoce a los parlamentarios, en una regulación dominada por el protagonismo de los grupos, aunque mediatizada por la exigencia de la firma del portavoz (supuestamente a los solos efectos de conocimiento) que requiere el artículo $110.1 \mathrm{del}$ Reglamento del Congreso ${ }^{47}$.

No obstante, son los grupos los que gozan en plenitud de la facultad de presentación de enmiendas, como señala Rubio Llorente ${ }^{48}$. En efecto, aunque pueden presentar enmiendas, —según el artículo 110.1 del Reglamento del Congreso-, los diputados y los grupos parlamentarios, han de hacerse algunas matizaciones a esta afirmación general: la presentación de enmiendas por los diputados requiere, según el Reglamento del Congreso (art. 110.1), la firma del portavoz del grupo a que pertenezca «a los meros efectos de conocimiento», trámite cuya omisión puede subsanarse antes del comienzo de la discusión en la Comisión; y las enmiendas a la totalidad sólo pueden ser presentadas por los grupos parlamentarios (art. 110.3).

En el momento actual, las enmiendas — como las proposiciones de ley- son presentadas exclusivamente por los grupos parlamentarios, habiendo desaparecido prácticamente las enmiendas de diputados, con excepción de las del Grupo Mixto, donde se presentan por tantos diputados como formaciones lo integran, también con la firma del portavoz.

El Tribunal Constitucional ha señalado que forman parte del núcleo de la función representativa parlamentaria, además del derecho a la iniciativa legislativa mediante la presentación de proposiciones de ley (sentencias 124/1995, 38/1999 FJ 3, 242/2006 FJ 5), el derecho a presentar enmiendas. Lo afirmó ya en el ATC118/1999: «pues la participación en el ejercicio de la función legislativa y el desempeño de los derechos y facultades que la acompañan constituyen una manifestación constitucionalmente, relevante del ius in officium del representante [STC 38/1990, fundamento jurídico 3. ${ }^{\circ}$ a)]» ${ }^{49}$, y lo reafirma con claridad en la reciente e importante sentencia 119/2011: «el derecho de en-

46 MERINO MERCHÁN, J.F., DE LA PEÑA RODRÍGUEZ, L., («Las facultades de calificación de las enmiendas por las Mesas de las Cámaras», cit., pág. 139) añaden a estos caracteres el incidental, en cuanto presentan una cuestión ligada a la iniciativa principal.

47 Véase al respecto GARCÍA-ESCUDERO MÁRQUEZ, P., «El parlamentario individual en un Parlamento de grupos: la participación en la función legislativa», Teoría y Realidad Constitucional, $\mathrm{n}^{\circ}$ 28, 2011, esp. págs. 222-226.

48 RUBIO LLORENTE, F., «El procedimiento legislativo en España: el lugar de la ley entre las fuentes del Derecho», Revista española de Derecho constitucional, nº 16, 1986, pág. 94.

49 No obstante, el ATC 12/1986 parece dar por bueno que las enmiendas deban presentarse por los grupos parlamentarios: «en ningún caso podría entenderse... que entre aquellas facultades [de los parlamentarios 
mienda que pertenece a los parlamentarios, en este caso a los Senadores, no es un mero derecho reglamentario sino un auténtico contenido central de su derecho de participación del art. 23.2 CE».

\section{Límites al derecho de enmienda en la reforma constitucional}

Los límites al derecho de enmienda en la reforma constitucional bien son impuestos por los Reglamentos de las Cámaras, bien derivan de las especialidades procedimentales que presentan los distintos tipos de reforma, bien responden a la exigencia de congruencia de las enmiendas con el texto de la iniciativa, como ha confirmado recientemente el Tribunal Constitucional en una revisión de su doctrina. A su vez, este último límite guarda relación con la exigencia de una legitimación especial para las iniciativas de reforma constitucional de origen parlamentario. En definitiva, examinaremos estos límites de lo formal a lo material, que a la vez resulta de lo más sencillo a lo más complejo.

\section{a) Probibición de enmiendas a la totalidad de devolución}

Conforme al artículo 126 del Reglamento del Congreso, no caben enmiendas a la totalidad de devolución sobre las proposiciones de ley previamente tomadas en consideración por la Cámara, sean de iniciativa parlamentaria, autonómica o popular, quedando excluidas por tanto de esta prohibición sólo las proposiciones de ley del Senado, que no han sido objeto de pronunciamiento por la Cámara Baja ${ }^{50}$. El artículo 146.1 RC se remite, para la tramitación de los proyectos y proposiciones de reforma constitucional, a las normas establecidas en el Reglamento para los proyectos y proposiciones de ley, con las especialidades contempladas en dicho artículo. Resulta, por tanto aplicable la exclusión de enmiendas de totalidad de devolución a las proposiciones de reforma constitucional tomadas en consideración, como es el caso de la Proposición de reforma del artículo 135 de la Constitución.

en el ejercicio de sus funciones de representación] se hallan las de presentar enmiendas individuales y no sólo a través del correspondiente Grupo parlamentario... máxime cuando ... ni se impide en absoluto a los diputados formular sus enmiendas, aunque éstas deban ser aceptadas y presentadas por el grupo parlamentario, ni consta que al hoy recurrente le fueran rechazadas efectivamente las que, según dice, tenía intención de presentar... Por lo demás, siendo [los grupos]...emanación de los partidos políticos, no puede olvidarse que los mismos se definen en el art. 6 de la Constitución como instrumentos o cauces fundamentales para la participación política, por lo que ni siquiera carecen de cierta justificación en el propio texto constitucional las decisiones adoptadas por el Presidente y la Junta de Portavoces del Congreso de los Diputados que ahora se impugnan».

50 Cabría pensar que este precepto viola la facultad de iniciativa del Senado, proclamada por el artículo 87.1 de la Constitución, subordinándola a la voluntad del Congreso, aunque lo que se hace en realidad es dar a las proposiciones de ley tomadas en consideración por dicha Cámara el mismo tratamiento que a los proyectos del Gobierno, sometidos en el debate y votación de totalidad a la posibilidad de aprobación tanto de enmiendas a la totalidad de devolución como de texto alternativo y, en este sentido, tal vez quepa aceptar lo que en un principio parece contrario a la Constitución, como decisión del Congreso, al comienzo de la tramitación, sobre la viabilidad de la iniciativa procedente de un sujeto ajeno. La posibilidad de devolución de una proposición de ley al Senado cobra su sentido en el caso de mayorías distintas en las dos Cámaras, en la que el Congreso, Cámara donde reside la mayoría que apoya al Gobierno, rechaza tramitar la proposición 
A este motivo respondió la inadmisión de la enmienda n 5 del Grupo ERC-IUICV, de supresión del artículo único de la Proposición de reforma, que materialmente pretendía tal devolución, pues de aprobarse la enmienda el resultado habría sido el fracaso de la iniciativa.

En realidad, no otra cosa pretendía la enmienda $n^{\circ}$ 20, de la Sra. Díez (Grupo Mixto), al proponer como texto del artículo 135 el actual de la Constitución, combinada con la enmienda $n^{\circ} 23$, de supresión de la disposición adicional única; pero en la medida que cada una de ellas es una enmienda parcial y en su conjunto no afectan a todo el texto de la proposición, al menos formalmente, pues ésta cuenta también con una exposición de motivos y una disposición final, fue admitida a trámite.

\section{b) Limites derivados de especialidades procedimentales}

En un doble aspecto deben contemplarse los límites derivados de especialidades procedimentales en el caso de la reforma constitucional:

- de una parte, ha de tenerse en cuenta que la legitimación exigida para la presentación de proposiciones de reforma constitucional es más rigurosa que para la presentación de enmiendas

- de otra parte, la Constitución prevé dos procedimientos de reforma distintos en los artículos 167 y 168, cuya tramitación parlamentaria difiere desde su inicio.

Veamos la repercusión de estos aspectos en la limitación del derecho de enmienda, que en ambos casos nos va a reconducir al límite siguiente, la necesidad de homogeneidad de las enmiendas con el texto de la iniciativa.

\section{b.1. Legitimación diferente para proposiciones de reforma y enmiendas}

Recordemos que el artículo 166 de la Constitución remite el ejercicio de la iniciativa de reforma constitucional a los términos previstos en los apartados 1 y 2 del artículo 87, relativo a la iniciativa legislativa. A su vez, el apartado 1 de este artículo declara: «La iniciativa legislativa corresponde al Gobierno, al Congreso y al Senado, de acuerdo con la Constitución y los Reglamentos de las Cámaras».

Los Reglamentos del Congreso y el Senado establecen una legitimación diferente para presentar proposiciones de ley y proposiciones de reforma constitucional. Pueden presentar las primeras un grupo parlamentario, 15 diputados o 25 senadores $^{51}$ (126.1 RC, 108.1 RS). Las segundas deben ir suscritas en el Congreso por dos grupos parlamentarios o por una quinta parte de los diputados (es decir, 70 diputados, $146.1 \mathrm{RC}$ ) y en el Senado por cincuenta senadores que no pertenezcan al mismo grupo parlamentario (152 RS).

La legitimación reforzada exigida para las proposiciones de reforma, que las eleva por encima de la iniciativa legislativa ordinaria, además de estar en consonancia con su carácter más trascendente —un abuso de este tipo de proposiciones por así decirlo «frivolizaría» la reforma constitucional, aun cuando ninguna llegara a ser tomada en consideración-, pretende que las iniciativas que se presenten tengan perspectivas de llegar a

51 Además de la Comisión General de las Comunidades Autónomas, de acuerdo con el artículo 56 s) del Reglamento del Senado 
buen término, teniendo en cuenta que las mayorías exigidas para su aprobación son también superiores a las requeridas para la aprobación de leyes.

En cuanto a las enmiendas, la legitimación para presentarlas es atribuida en general por los Reglamentos de nuestras Cámaras a los parlamentarios y a los grupos, siendo ejercida esta facultad en el momento actual exclusivamente por los últimos.

Si el trámite de enmiendas no se utiliza conforme a su finalidad de introducir modificaciones en una iniciativa presentada y —en el caso de las proposiciones — tomada en consideración por la Cámara, sino que se emplea para introducir elementos ajenos a la misma, en el supuesto de la reforma constitucional se produce claramente un fraude de procedimiento, en la medida en que los grupos parlamentarios individuales pueden esquivar así la exigencia de que deban concurrir dos grupos en la presentación de proposiciones de reforma.

Para que el fraude no se produzca, las enmiendas deben ser tales y no iniciativas, esto es, referirse al texto de la proposición o guardar una clara conexión material con la misma. No nos extendemos aquí sobre esta cuestión, que vamos a tratar con más detalle más adelante, incluyendo la reciente revisión de la doctrina del Tribunal Constitucional. Bástenos dejar apuntada la exigencia de homogeneidad y congruencia de las enmiendas con el texto tomado en consideración para no incurrir en un fraude de legitimación para la iniciativa de reforma constitucional.

Tal vez en este apartado debemos situar aquellas enmiendas, con redacción diversa, que pretendían el sometimiento a referéndum de la reforma aprobada, por interpretarse que materialmente constituían una reforma del Título X de la Constitución. La inadmisión por las Mesas se fundamenta «por suponer una alteración del procedimiento de reforma constitucional contemplado en el Título X de la Constitución».

\section{b.2 Procedimientos parlamentarios distintos para la tramitación de las reformas constitucionales simples o agravadas}

La Constitución, en los artículos 167 y 168, establece dos procedimientos distintos de reforma constitucional que difieren no sólo en cuanto a las mayorías requeridas para su aprobación y el carácter obligatorio o facultativo del referéndum, sino también en su tramitación parlamentaria.

Esta diferencia halla reflejo en los Reglamentos de las Cámaras. Por fijarnos sólo en el inicio del procedimiento parlamentario, el artículo 146.1 del Reglamento del Congreso se remite, para la tramitación de los proyectos y proposiciones de reforma constitucional a que se refieren «los artículos 166 y 167 de la Constitución», a las normas establecidas para los proyectos y proposiciones de ley, esto es, al procedimiento legislativo, regulando sólo la señalada peculiaridad de la legitimación, la mayoría requerida para la aprobación y la resolución de conflictos con el Senado. En cambio, el artículo 147 RC introduce como primer trámite para los proyectos y proposiciones de ley que postulen una reforma afectada por el artículo 168 de la Constitución un debate ante el Pleno, que se ajustará a las normas previstas para los de totalidad, seguido de la votación del "principio de revisión», sin que se abra en esta primera legislatura trámite de enmiendas, pues la aprobación de aquél por mayoría de dos tercios va seguida de la disolución de la Cámara. 
Cierto es que, si trazamos un paralelismo con otro supuesto de disparidad procedimental, en el caso de las inicativas legislativas pueden introducirse enmiendas de carácter orgánico prácticamente hasta el último momento del procedimiento — a través de enmiendas en el Senadouna iniciativa de esta naturaleza. Pero, aparte de que ello encuentra apoyo en el artículo 130 del Reglamento del Congreso, la disparidad procedimental se produce en el momento final de la aprobación, no en el inicio de la tramitación. Y volvemos al supuesto anterior, si el texto introducido en un proyecto o proposición de reforma constitucional tuviera que ser desglosado como iniciativa distinta, debería haberse presentado como proposición de reforma y no como enmienda, y haber cumplido en consecuencia con los requisitos iniciales de legitimación.

Distintas enmiendas pretendían incorporar al texto de la reforma la modificación de preceptos incluidos en el ámbito del artículo 168 de la Constitución, señaladamente del artículo 2. La inadmisión se produce «en la medida en que postulan una reforma de un artículo para cuya reforma el artículo168 exige un procedimiento agravado».

\section{c) Limites derivados de la exigencia de homogeneidad y congruencia entre las enmiendas presentadas y la iniciativa original}

Ninguna enmienda ha sido inadmitida por la Mesa del Congreso o del Senado por falta de homogeneidad o congruencia con la iniciativa a la que se refiere. Y sin embargo, habría podido aplicarse la doctrina revisada del Tribunal Constitucional, contenida en recientes sentencias, sobre los límites del derecho de enmienda.

Hasta ahora, la doctrina del Alto Tribunal podía ser calificada de oscilante - por más que haya querido justificarla en la sentencia 119/2011 — en cuanto a la necesidad o no de conexión material de las enmiendas con el texto legislativo enmendado. Hemos mantenido, pese a ello, la necesidad de que las enmiendas respeten los principios citados de homogeneidad y congruencia ${ }^{52}$, muy en particular en el procedimiento agravado de reforma constitucional ${ }^{53}$.

Es conocida la sentencia 99/1987, sobre la Ley 30/1984, de medidas para la reforma de la función pública, en la que el Tribunal afirmaba que «no existe ni en la Constitución ni en los Reglamentos de ambas Cámaras norma alguna que establezca una delimitación material entre enmienda y proposición de ley. Ni por su objeto, ni por su contenido, hay límite alguno a la facultad que los miembros de las Cámaras tienen para presentar enmiendas, exceptuadas las que, tanto para las enmiendas como para las proposiciones de ley, fijan los arts. 84 y 134.6 de la Constitución para asegurar un ámbito de acción propia al Gobierno».

52 GARCÍA-ESCUDERO MÁRQUEZ, P., El procedimiento legislativo ordinario en las Cortes Generales, cit., págs. 238 y ss.

53 Para evitar que por vía de enmienda se introduzcan modificaciones no previstas en el principio de reforma aprobado por la primera legislatura y ratificado por la segunda, que esquivaran las reglas de procedimiento establecidas por el artículo 168 de la Constitución. Recuérdese que en la tramitación de las leyes de armonización, que pueden presentar cierto paralelismo procedimental, el artículo 168.3 RC declara no admisibles las enmiendas que impliquen contradicción con el previo pronunciamiento de la Cámara de apreciación de la necesidad. GARCÍA-ESCUDERO MÁRQUEZ, P., El procedimiento agravado de reforma de la Constitución de 1978, CEPC, Madrid, 2007, págs. 101-102. 
Esta doctrina fue ratificada por el Pleno del Tribunal en la sentencia 194/2000, de 19 de julio, en el recurso de inconstitucionalidad contra la disposición adicional cuarta de la Ley 8/1989, de 13 de abril, de tasas y precios públicos, en que se regulaba, mediante una enmienda introducida en el Senado, el tratamiento fiscal de las diferencias de valor resultantes de la comprobación administrativa a efectos del impuesto sobre transmisiones patrimoniales. El Tribunal afirmó que los artículos 90.2 CE y 107 RS «no limitan el alcance de las enmiendas senatoriales que modifiquen el texto del proyecto enviado por el Congreso de los Diputados ${ }^{54}$, rechazando que el procedimiento empleado hubiera restringido las facultades del Congreso de los Diputados.

En la sentencia 119/2011, el Tribunal justifica los dos pronunciamientos expuestos - ante supuestos similares en que el precepto impugnado había sido incluido como enmienda senatorial — en que se había tomado en consideración, por un lado, la alegación de los recurrentes de que no respondía a la finalidad concreta de la iniciativa legislativa, pero sin negar que existía una conexión material, y por otro la inexistencia de previsión expresa en el Reglamento del Senado al respecto, lo que llevaba a concluir «en defensa del amplio margen de autonomía y valoración de las Cámaras, que no cabe derivar de la Constitución la existencia de unos límites al alcance de las enmiendas senatoriales que impidan innovaciones en la finalidad de la iniciativa legislativa, de modo que la negativa a valorar la concurrencia de una conexión material u homogeneidad entre la enmienda y la iniciativa legislativa como requisito de admisibilidad de una enmienda no supondría un infracción de la legalidad parlamentaria».

Junto a estos dos pronunciamientos, el Tribunal destaca tres resoluciones dictadas en procedimientos de amparo interpuestos por la vía del artículo 42 LOTC contra decisiones de Mesas de Parlamentos autonómicos, en las que fue más proclive a reconocer la necesidad de homogeneidad de las enmiendas con las iniciativas enmendadas, confirmando la constitucionalidad de las valoraciones de las respectivas Mesas no sólo en aquellos supuestos en que el Reglamento de la Cámara lo tenía previsto de manera expresa (STC 23/1990, sobre el rechazo por la Mesa de las Cortes Valencianas de una enmienda de texto alternativo a un proyecto de Proposición de ley orgánica de modificación del Estatuto de Autonomía por carecer de congruencia con el texto a que iba dirigida; y ATC 275/1993, en relación con la inadmisión por la Mesa de la Junta General del Principado de Asturias de 23 enmiendas a la propuesta de Proposición de ley orgánica de reforma del Estatuto de Autonomía, con fundamento en la desconexión entre el contenido de las enmiendas y el texto de la propuesta, pretendiendo en realidad una enmienda a la totalidad con texto alternativo ${ }^{55}$ ), sino también en aquellos casos en que no se establecía una concreta previsión al respecto: ATC 118/1999, sobre el rechazo por la Mesa de la Asamblea Regional de Cantabria de dos enmiendas por incongruentes con el texto que se pretendía enmendar. El auto hacía extensiva a las enmien-

54 «La tesis de los recurrentes, según la cual las enmiendas de adición formuladas en el Senado que supongan una innovación importante deben seguir el cauce legal correspondiente a los proyectos de ley puede invocar en su favor razones de corrección técnica y buena ordenación del procedimiento legislativo e incluso puede resultar más acorde con la posición constitucional atribuida al Senado en nuestro ordenamiento, pero no se deduce necesariamente del bloque de constitucionalidad» (FJ 3)

55 «Ignorando con ello que la superación de una proposición del debate de toma en consideración supone ya la realización de ese trámite parlamentario, que no puede en consecuencia ser reabierto» (FJ 2) 
das parciales la jurisprudencia establecida en la STC 23/1990, sobre la exigencia de correlación material con el texto enmendado en el caso de las enmiendas a la totalidad de texto alternativo. La importancia de este auto residía en que reconocía la necesidad de concurrencia de los dos requisitos de homogeneidad y congruencia de las enmiendas que reclamaba la doctrina ${ }^{56}$.

En la importante sentencia 119/2011, el recurso de amparo ha sido avocado por el Pleno del Tribunal Consitucional al amparo del artículo 13 de la LOTC, según dice expresamente (FJ 6) para revisar la jurisprudencia sentada por el Pleno en las sentencias 99/1987 y 194/2000 y clarificarla a la vista de la sentencia 23/1990 y de los autos 275/1993 y 118/1999, clarificación y revisión especialmente convenientes al tratarse de resoluciones de distinta naturaleza y dictadas tanto en recursos de inconstitucionalidad como en recursos de amparo.

A los efectos que aquí nos interesan, no referidos exclusivamente a las enmiendas del Senado (a las que, dada la naturaleza del recurso, debe circunscribirse la doctrina contenida en la sentencia), destaquemos el resumen siguiente (FJ 6): «incluso en los supuestos en que el Reglamento de la Cámara legislativa correspondiente, como es el del Senado, guarde silencio sobre la posibilidad de que la Mesa respectiva verifique un control de homogeneidad entre las enmiendas presentadas y la iniciativa legislativa a enmendar, esta exigencia se deriva del carácter subsidiario que toda enmienda tiene respecto al texto enmendado, de la lógica de la tramitación legislativa y de una lectura conjunta de las previsiones constitucionales sobre el proceso legislativo», no considerando el Tribunal novedosa la conclusión de que la Constitución impone, aun implícitamente, la existencia de determinados límites materiales en la actividad legislativa, por haberse aplicado con anterioridad a las leyes de presupuestos.

El Tribunal matiza, no obstante su doctrina, reconociendo un amplio margen de apreciación a las Mesas de las Cámaras para determinar la existencia de conexión material entre enmienda e iniciativa, pero esta tarea «cuando lo que se plantea es precisamente una falta absoluta de conexión, no puede reducirse a una simple decisión injustificada sino a una valoración motivada, aunque sea sucintamente, sobre la existencia o no de dicha conexión mínima ${ }^{57}$. Esta valoración, por otra parte, debe hacerse en el seno del procedimiento legislativo, en el que las dos Cámaras no están en la misma posición, por lo que «la aplicación de esta doctrina en cada caso no puede hacerse sin valorar que el Congreso y el Senado no actúan en el mismo momento ni son exactamente las mismas sus facultades formales». Para supuestos de urgencia, el Tribunal recuerda que existe la posibilidad de acudir a otros mecanismos, como el decreto ley o los procedimientos de urgencia o lectura única ${ }^{58}$.

56 Así, ARCE JANÁRIZ, A., «El derecho de enmienda visto por el Tribunal Constitucional», Revista española de Derecho Constitucional, no 41, 1994, pág. 163.

57 «...pues sólo cuando sea evidente y manifiesto que no existe tal conexión deberá rechazarse la enmienda, puesto que en tal caso se pervertiría la auténtica naturaleza del derecho de enmienda, ya que habría pasado a convertirse en una nueva iniciativa legislativa» (FJ7).

58 «Dicho de otra forma, aceptar el ejercicio del derecho de enmienda como mecanismo paliativo o sustitutivo de las insuficiencias que pudieran tener los procedimientos legislativos supondría tanto como hacer caso omiso de la voluntad del constituyente» que ya ha determinado los instrumentos con los que hacer frente a las urgencias legislativas. «Desatender los límites constitucionales bajo el paraguas de la urgencia normativa no 
El Tribunal cierra su razonamiento destacando que el derecho de enmienda de los parlamentarios no es un mero derecho reglamentario sino un auténtico contenido central de su derecho de participación del artículo 23.2 de la Constitución (FJ 8), que se ve lesionado si el debate se articula de forma que la introducción de más enmiendas haga imposible la presentación de alternativas y su defensa ${ }^{59}$.

Esta sentencia, tan reciente, habría podido ser aplicada por las Mesas de las Cámaras respecto de las enmiendas carentes de homogeneidad con la Proposición de reforma del artículo 135 de la Constitución (por ejemplo, las relativas al artículo 2 y al derecho de autodeterminación de Cataluña y País Vasco, inadmitidas por otros motivos), y también de congruencia, por tratarse de una proposición tomada en consideración (recuérdese la sentencia 23/1990). Como declara la aún más reciente sentencia 136/2011, de 13 de septiembre, confirmando la doctrina revisada, «la materia y el objeto del procedimiento lo delimita el autor de la iniciativa» (FJ 6). «Toda enmienda parcial tiene que tener un carácter subsidiario o incidental respecto del texto a enmendar, de modo que una vez que una iniciativa ha sido aceptada por la Cámara como texto de deliberación, no cabe alterar su objeto mediante las enmiendas al articulado... No caben enmiendas al articulado ajenas a la materia de la iniciativa, esto es, que no guarden una conexión de homogeneidad mínima con la misma. Cuando el ejercicio del derecho de enmienda al artículado no respete dicha conexión mínima de homogeneidad con el texto enmendado se estará afectando, de modo contrario a la Constitución, al derecho del autor de la iniciativa» (FJ 8). ${ }^{60}$

Es precisamente en la tramitación de las reformas constitucionales donde puede aplicarse con mayor rigor la exigencia de homogeneidad y congruencia de las enmiendas con la iniciativa, y no sólo en el caso de las que han de tramitarse conforme al artículo 168 de la Constitución ${ }^{61}$ (téngase en cuenta, por otra parte, que la exigencia de un procedimiento diferenciado no implica forzosamente la incongruencia, véanse a título de ejem-

deja de ser una lesión constitucional por mucho que pueda parecer conveniente coyunturalmente. Una buena política legislativa puede evitarlo y cuando excepcionalmente no sea posible debe asumir el coste democrático que pueda tener pero no forzar la Constitución» (FJ 7).

59 Tal vez la conexión con el derecho de enmienda de los demás parlamentarios no fuera el motivo más acertado para declarar la inconstitucionalidad. En efecto, las enmiendas, cualesquiera que sean —homogéneas o heterogéneas - se debaten y votan, en comisión y en Pleno. Tampoco una enmienda homogénea y congruente que plantee una cuestión imprevista e imprevisible — y por tanto nueva— puede ser enmendada, salvo por vía de transacción en los términos reglamentarios. El argumento para la inconstitucionalidad debiera haber estribado en la vulneración del principio de seguridad jurídica que produce la inclusión de elementos heterogéneos en una ley, lo que no ha considerado contrario a la Constitución el Tribunal en la sentencia 136/2011.

60 Lamentablemente, en esta segunda sentencia, el Tribunal no ha mantenido un criterio riguroso y clarificador respecto de las leyes de contenido heterogéneo — singularmente, las llamadas leyes de medidas, una de las cuales constituía el objeto del recurso-, pues no ha considerado que lesionen la seguridad jurídica. Coincido plenamente con el voto particular del magistrado Aragón Reyes, en que el recurso ofrecía al Tribunal la ocasión de poner coto a la práctica de estas leyes. Aragón fundamenta la inconstitucionalidad de la ley impugnada en la vulneración del principio democrático reconocido en el artículo 1.1 de la Constitución y de su proyección sobre el procedimiento legislativo.

61 Sobre la necesidad de una calificación material de las enmiendas al tramitarse una reforma constitucional en la segunda legislatura, para evitar que excedan los límites del principio de reforma aprobado en la primera y ratificado en aquélla, puede verse GARCÍA-ESCUDERO MÁRQUEZ, P., El procedimiento agravado de reforma de la Constitución de 1978, cit., pág. 102. 
plo las leyes orgánicas complementarias de otras ordinarias). Como se ha señalado con anterioridad, admitir enmiendas sin conexión material con la iniciativa permite obviar la legitimación requerida para presentar proyectos o proposiciones de reforma.

De hecho, el Tribunal Constitucional, en el Auto repetidamente citado, en cuanto a la inadmisión de la enmienda a la totalidad de ERC-IU-ICV se apoya en la necesidad de homogeneidad de las enmiendas con la iniciativa y afirma que los recurrentes presentaron una iniciativa de reforma de la Constitución distinta a la que se estaba tramitando y no un texto alternativo a la reforma del artículo 135 de la Constitución, habiendo sido ya aceptada por el Tribunal la inadmisión a trámite de una enmienda que se separa del objeto de la tramitación en curso en la sentencia 23/1990, posición confirmada en la sentencia 119/2011.

\section{CONCLUSIÓN}

En la primera parte de este trabajo, he concluido que el procedimiento utilizado para la tramitación de la Proposición de reforma del artículo 135 de la Constitución no ha sido el adecuado. No sólo desde el punto de vista puramente formal: se han reproducido algunas quejas de las minorías parlamentarias sobre la ausencia de negociación con ellas por parte de los dos grupos mayoritarios, autores de la iniciativa, lo que ha propiciado la inexistencia de consenso, expresada mediante la legítima votación en contra o a través de la no participación en su aprobación.

Si el consenso inspiró el proceso constituyente, debería mantenerse también en las reformas constitucionales o, al menos, tomarse la molestia de intentarlo. Lo que Alzaga denomina «el temor a la instauración de una dinámica de la discordia ${ }^{62}$ » no debe hacerse realidad cuando de una reforma de la Constitución se trata. Como también afirma este autor, «el óptimo funcionamiento de nuestro sistema constitucional implica un esfuerzo colectivo de concordia». Y parece que este esfuerzo no se ha hecho con el resto de los grupos, una vez concordadas las voluntades de los dos mayoritarios, a los que no obstante ha de reconocerse que integraban más del noventa por ciento de los miembros de las Cámaras.

Como se ha apuntado, los propios procedimientos parlamentarios utilizados (lectura única, urgencia, miniplazos de enmiendas) no han permitido paliar esa ausencia de negociación previa que denuncian los grupos minoritarios, incluso han llegado a impedir la posibilidad de alcanzar alguna transacción parcial a lo largo de la tramitación ${ }^{63}$.

En lo que se refiere a las enmiendas presentadas, éstas son significativas, porque revelan por dónde van las aspiraciones de reforma constitucional de las minorías. La inadmisión de algunas de aquéllas por las Mesas de las Cámaras, según hemos analizado, está justificada, en la medida en que han traspasado los límites del derecho de enmienda en la reforma constitucional, aunque se haya querido explotar políticamente presentando

62 ALZAGA VILlAAMIL, O., El consenso (del proceso constituyente a las prácticas postconstitucionales), Real Academia de Ciencias Morales y Políticas, Madrid, 2010, pág. 98.

63 También técnicamente el texto de la reforma podría haber mejorado con un examen más sosegado, véase a título de ejemplo la disposición adicional única de contenido parcialmente transitorio y parcialmente referido a la entrada en vigor, que debería figurar en la disposición final única. 
aquella como una maniobra de veto. Incluso deberían haber ido más allá los órganos rectores de las Cámaras, aplicando la nueva doctrina del Tribunal Constitucional sobre la homogeneidad y congruencia de las enmiendas con la iniciativa a la que afectan, contenida entonces en la sentencia 119/2011 y ahora también en la 136/2011.

No podemos dejar de destacar, para finalizar, la ironía de que por la puerta falsa de la reforma del artículo 135 se haya introducido en la Constitución la primera mención a la Unión Europea (e incluso, según De Esteban, a las Comunidades Autónomas como un hecho adquirido, mientras que hasta ahora la mención no era más que una promesa de futuro $\left.^{64}\right)$. En definitiva, dos de las reformas constitucionales anunciadas por el entonces candidato a la Presidencia del Gobierno Rodríguez Zapatero en su debate de investidura en abril de 2004, que no habían llegado a buen término en siete años por falta de acuerdo entre el Partido Socialista y el Partido Popular, se resuelven ahora en un mes y de pasada, sin que tal fuera el objetivo de la reforma.

TITLE: The Reform of art. 135 of the Spanish Constitution

ABSTRACT: After the introduction of the "European restriction" to public deficit, resulting from the Treaty of Maastricht and the Stability and Growth Pact, the Autonomous Communities have been subject to formal fiscal rules with regard to the deficit and the debt, as well as the management of their budgets. However, this regulation did not prevent some Autonomous Communities failed to comply with the budgetary stability objectives, probably because it lacked an effective system of sanctions. This paper examines the scope of the constitutional amendment of article 135, and focuses particularly on the margin of maneuver that new article 135 gives the State to impose the regional governments meet the deficit and debt limits.

Resumen: Tras el establecimiento de la "restricción europea" al déficit público, la derivada del Tratado de Maastricht y del Pacto de Estabilidad y Crecimiento, las Comunidades Autónomas han estado sujetas a reglas fiscales relativas al déficit y a la deuda, así como a la gestión de sis presupuestos. Esta normativa, sin embargo, no evitó que algunas Comunidades incumplieran los objetivos se estabilidad persupuestaria probablemente porque carecía de un eficaz sistema de sanciones. Este trabajo examina el alcance de la reforma del art. 135 de la Constitución, y especialmente se centra en el margen de maniobra que el nuevo artículo atribuye al Estado para imponer a los gobiernos autonómicos el cumplimiento de los límites de déficit y deuda.

KEY WORDs: Fiscal federalism, budgetary estability, public deficit, debt.

Palabras Clave: Federalismo fiscal, estabilidad presupuestaria, déficit público, deuda.

FECHA DE RECEPCIÓN: 15.12.2011 FeCHA DE ACEPTACIÓN: 15.02.2012.

64 DE ESTEBAN, J., «El desbloqueo de nuestra Constitución», El Mundo, 27 de agosto de 2011. 